\title{
THE PERCEPTION OF SELECTED ASPECTS OF SMILE ESTHETICS - SMILE ARCS AND BUCCAL CORRIDORS
}

\author{
A Thesis \\ Presented in Partial Fulfillment for the \\ Degree Master of Science in the \\ Graduate School of The Ohio State University
}

By

Sanjay M. Parekh, D.D.S.

$* * * * * *$

The Ohio State University

2005

Master's Examination Committee:

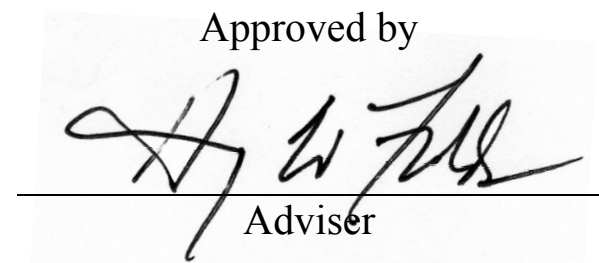

Dr. Stephen Rosenstiel

Graduate Program in Dentistry 


\begin{abstract}
One of the primary goals of orthodontics is the attainment of ideal facial and dental esthetics. Recently, the field of orthodontics has experienced a "paradigm shift" to focus more on esthetics, with specific emphasis to the soft tissues around the mouth. The purpose of this study was to evaluate the effects of changes in smile arcs and buccal corridors, and interactions on the perceptions of smile esthetics as it relates to orthodontists versus a lay population. The specific aims were: 1) To develop a digital model that can be manipulated in a quantifiable manner to present the variables of interest (i.e., smile arcs and buccal corridors) to orthodontists and laymen 2) To quantitatively evaluate the effects of changes in smile arcs and buccal corridors and combinations thereof using the digital model on the perceptions of smile esthetics as judged by a sample of orthodontists and laymen via a web based survey 3) To assess the effects of changes in smile arcs and buccal corridors and combinations thereof on the perceptions of smile esthetics acceptability as judged by a sample of orthodontists and laymen via a web based survey 4) To determine the possible effects of orthodontists and laymen characteristics on the variables related to the esthetics of the smile.

The approach used in this research was to present experienced orthodontists with digital images of male and female smiles so they could manually adjust the smile arc and buccal corridors to match criteria we requested. Later, these data were used to create a
\end{abstract}


group of standard images ( 9 male and 9 female) that demonstrated the medians of the categories of smile arc and buccal corridors for rating by a larger group of both orthodontists and laypersons. All images were presented via interactive, web based surveys.

The results of the attractiveness study indicate that both laypersons and orthodontists prefer smiles in which the smile arc parallels the lower lip and buccal corridors are minimal. Significantly lower attractiveness ratings were found for smiles with flat smile arcs and excessive buccal corridors. Flattening of the smile arc overwhelms the deleterious effects of excessive buccal corridors on attractiveness ratings. Based on the results of this study, care should be taken not to produce an excessively flat smile arc during orthodontic treatment.

While the acceptability data follows trends in attractiveness, there exists a broad range of acceptability that is not evident in the attractiveness data. Orthodontists and laypersons both found smiles with excessive buccal corridors to be less acceptable than those with ideal or absent buccal corridors, but they were still acceptable over $70 \%$ of the time. Flat smile arcs were only acceptable $50-60 \%$ of the time, while smiles with ideal and excessive smile arcs were acceptable $84-95 \%$ of the time. When studying dental and facial esthetics, the clinician must realize that although attractiveness scores may indicate a detrimental result, that result may still be acceptable to a majority of people. 


\section{ACKNOWLEDGMENTS}

I would like to thank my thesis committee, Dr. Henry Fields, Dr. Stephen Rosenstiel, and Dr. Michael Beck for their guidance, wisdom, and dedication to this project. I consider myself extremely fortunate to have worked with such world-class individuals. It is because the insight of these great individuals, we were able to able to produce such a unique and fascinating study. Dr. Rosenstiel provided valuable advice in conducting a revolutionary survey design using state of the art technology. While Dr. Beck provided the statistical knowledge, I must thank him for his continual encouragement and confidence in me. I would especially like to thank Dr. Fields for his patience and understanding throughout the project, and for his countless hours required to develop this study from an idea to reality.

I thank my classmates, Greg Anderson, Nate Downey, Janice Struckhoff, and Wyatt Wood, for their friendship. My time in residency at The Ohio State University will always be filled with the many fond memories we have made during the last three years. I could not have asked for a better group of people with whom I could complete my orthodontic training.

I thank all the participants in the study, both laypersons and orthodontists, whose expedience and reliability, allowed my data collection to go so smoothly. I thank all my 
friends and family who participated, and solicited others to participate as well. It is because of you that we received such an excellent response and result.

I thank Dr. Michael Reznik, an orthodontist from my hometown in Odessa, TX, for opening my eyes to the field of orthodontics and encouraging me to purse what I feel is the greatest job in the world.

I would like to thank my family for their unconditional love, support and guidance throughout the years. Your belief in me has been a great motivator and inspiration. Finally, and most importantly, I must thank my father, Dr. M.C. Parekh. It is because of your persistence and encouragement, wisdom and knowledge, and real life example, I have achieved this goal. Thank you for the sacrifices you made in your life to ensure I reach my dreams. I am forever grateful for you and what you have done for me. 
Dedicated to my parents, my brother, and my sister 


\title{
VITA
}

\author{
July $2,1976 \ldots \ldots \ldots \ldots \ldots \ldots \ldots$ Born, Odessa, Texas

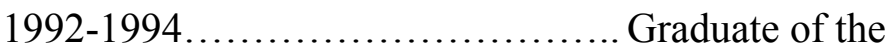 \\ Texas Academy of Mathematics and Science \\ University of North Texas \\ Denton, Texas \\ 1994-1996....................... B.S., Biochemistry \\ Texas Christian University \\ Fort Worth, Texas \\ $1998-2002 \ldots \ldots \ldots \ldots \ldots \ldots \ldots \ldots \ldots$ D.D.S. \\ The Texas A\&M University Health Science Center \\ Baylor College of Dentistry \\ Dallas, Texas \\ 2002-2005.......................... Graduate Resident in Orthodontics \\ The Ohio State University \\ Columbus, Ohio
}

\section{FIELDS OF STUDY}

Major Field: Dentistry

Specialty: Orthodontics 


\section{TABLE OF CONTENTS}

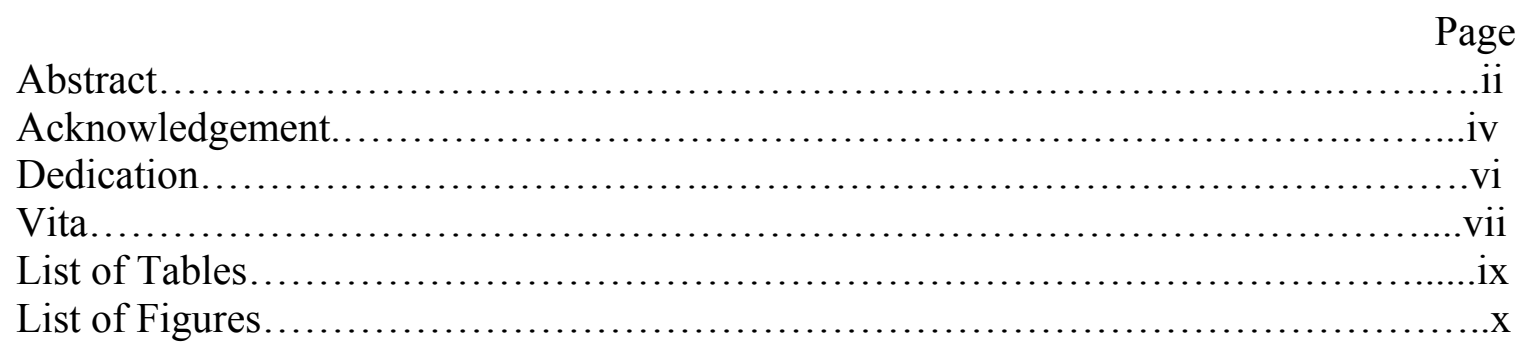

Chapters:

1. Introduction and Comprehensive Literature Review.........................1

2. Materials and Methods.................................................... 15

3. Manuscript: The Attractiveness of Variations in Smile Arc and Buccal Corridor Space as Judged by Orthodontists and Laymen..........................23

4. Manuscript: The Acceptability of Variations in Smile Arc and Buccal Corridor Space as Judged by Orthodontists and Laymen............................43

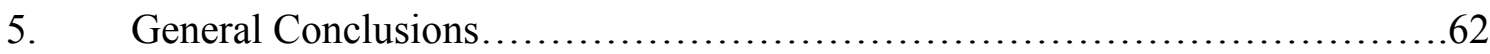

List of References..........................................................64

Appendix A: Additional Tables and Figures.................................. 72 


\section{LIST OF TABLES}

Tables $\quad$ Page

4.1 Logistic Regression with GEE for Repeated Measures.......................55

4.2 Significant Interactions Based on Logistic Regression.....................56

A.1 Pilot Survey Responses........................................... 73

A.2 Distribution of Responses......................................... 74

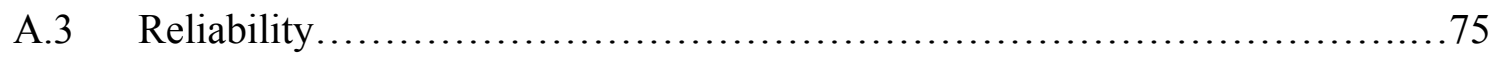

A.4 ANOVA Summary for Attractiveness................................ 76

A.5 Buccal Corridor Percentages.......................................... 77 


\section{LIST OF FIGURES}

$\begin{array}{ll}\text { Figures } & \text { Page }\end{array}$

3.1 Pilot Survey Example and Responses ....................................

3.2 Main Survey Female Composite Images..................................37

3.3 Model Gender X Buccal Corridor (BC) X Smile Arc (SA) .....................38

3.4 Rater Gender X Group X Buccal Corridor (BC) X Smile Arc (SA)...............39

4.1 Pilot Survey Example and Responses................................57

4.2 Main Survey Female Composite Images..................................58

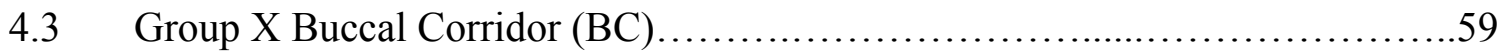

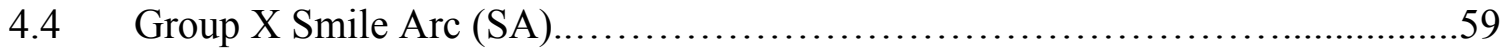

4.5 Buccal Corridor (BC) X Smile Arc (SA) .................................60

A.1 Main Survey Female Composite Images..................................78

A.2 Main Survey Male Composite Images................................... 79

A.3 Main Survey Example............................................... 80 


\section{CHAPTER 1}

\section{INTRODUCTION}

Facial and dental esthetics have become ever increasingly important during the last decade. Recently, the field of orthodontics has experienced a "paradigm shift" to focus more on esthetics, with specific emphasis on soft tissues around the mouth. ${ }^{1}$ Edward Angle, ${ }^{2}$ who many recognize as the father of orthodontics, believed that ideal dental and facial esthetics would naturally result from developing an ideal occlusion. Today, most orthodontists understand that the attainment of optimal esthetics is not that simple and also involves how the teeth relate to the intraoral soft tissues and to the soft tissues of the face. However, despite this heightened emphasis, there exists little scientific evidence regarding the components of an esthetic smile. Many current theories and clinical practices have evolved from anecdotal evidence or from restorative dentistry

concepts, ${ }^{3-5}$ but many remain unsubstantiated. Although the concept of the smile is central to orthodontics and dentistry, the limited research available on smile esthetics has forced practitioners to make clinical decisions that are not based on either facts that represent a standard embraced by the profession or on lay opinion and acceptability data. The overall objective of this study is to begin to define the elements that comprise an 
esthetic smile and the variables that interact with those elements so that orthodontists, as well as other dental professionals, can effectively establish acceptable treatment goals.

Such a study has been difficult in the past due to the inability to standardize a realistic model and alter the variables of interest. With the evolution of digital imaging, however, manipulation of the variables can be accomplished in a reliable and quantifiable manner.

Sarver and Ackerman ${ }^{6}$ acknowledge three basic requirements for assessing dental and facial esthetics:

1. A dynamic and static 3-dimensional evaluation of the face derived primarily from the clinical exam of the patient.

2. A determination of lip-tooth relationships and anterior tooth display at rest during facial animation.

3. An analysis of the dental and skeletal volume of the face and its effects on the soft tissue facial mask.

Sarver and Ackerman go further to state that this process can be enhanced by the use of computer simulation. They have piloted some of the studies. Of these, digital imaging methodology can be used most effectively to evaluate the second requirement.

Additionally, others have applied similar methodology to dental morphology alteration. ${ }^{7-9}$ The proposed study will attempt to use digital technology to manipulate hard and soft tissue components of the smile in order to determine whether historically identified variables have an impact on esthetic ratings and acceptability so the results can be used by clinicians. 


\section{COMPREHENSIVE LITERATURE REVIEW}

\section{AND}

\section{STATEMENT OF THE PROBLEM}

In 1936, Dale Carnegie ${ }^{10}$ wrote a book, How to Win Friends and Influence People. One of the most important ways was to smile, “.... a real smile, a heartwarming smile, one that comes from the heart."

Although the focus of this work is the smile and its elements, one must appreciate the smile in the context of facial and dental esthetics. Numerous studied have shown the effect of dental attractiveness on psychosocial well being ${ }^{11-15}$ and interpersonal relationships. Shaw showed that dentofacial attractiveness has a strong influence on a young adult and their preference for friends. ${ }^{16}$ It has also been shown that when compared with less attractive people, more attractive people are seen as more popular, ${ }^{17-}$ ${ }^{20}$ intelligent, ${ }^{21}$ sociable, ${ }^{22,23}$ and have greater dating potential. ${ }^{24,25}$

For centuries, people have tried to quantify the elements that make a face and smile esthetic. Peck et $\mathrm{al}^{26}$ describes the evolution of facial esthetic ideals from early ancient civilizations in Egypt, China, and Greece, through the Renaissance, and up until the present date. A number of different concepts have been used to quantify facial esthetics. One of the most well known is the Golden Proportion, a mathematical concept originally introduced by the Egyptians. It has often been used to categorize the elements of the ideal smile and facial form. While not limited to facial esthetics, this proportion has often been noted in many classical art forms. Others have attempted to base perfect 
proportionality on the square root of two and other derivatives of the Fibonacci sequence. ${ }^{27-29}$

Many of these mathematical formulas and esthetic concepts are a pseudo science and remain unsubstantiated. Prosthodontists and orthodontists in the $19^{\text {th }}$ and $20^{\text {th }}$ century based their treatment on many of these concepts but had little or no scientific basis for doing so. Ricketts ${ }^{22,28}$ originally tried to apply such a ratio to facial esthetics stating that the ratio of forehead to eye, and eye to mention should equal the 1:1.618 divine proportion. Others have tried to apply such ratios to the dimensions of the maxillary anterior teeth, but this has been subsequently disproved. ${ }^{30}$

Shaw ${ }^{16,31}$ studied changes in social attractiveness based on changes in dental and facial appearance. In his study, Shaw had individuals rate photographs of attractive and unattractive males and females with dental changes such as the prominence of the incisors, missing lateral incisors, severely crowded incisors, and unilateral cleft lip. Changes in dental and facial morphology were found to affect social attractiveness, with facial esthetics having a greater impact than dental esthetics.

The study of smile esthetics represents an intermediate between dental and facial esthetics. As detailed below, the evolution of smile esthetics took an interesting course, one which emerged from the inside out. Many of the early studies focused on the size, shape, and proportions of teeth. As these ideas developed, the focus changed to encompass the importance of symmetry as well as the periodontal architecture. In the present day, the current focus is not only on the teeth and periodontium, but their relationship to the perioral structures, specifically the extraoral soft tissues. 
The principles inherent to creating an ideal smile originated from concepts developed in denture esthetics. As early as 1914 , Williams ${ }^{24}$ concluded that human teeth could be classified into three principal shapes: rectangular, triangular, and ovoid. Williams claimed that in order to produce the most harmonious reconstruction, tooth selection should be based upon the shape of the subjects head when turned upside down.

Frush and Fisher ${ }^{32}$ took this idea a step further in an effort to harmonize teeth with the patient's gender, personality and age. It is here that the idea that women should have round, soft, and delicate teeth and that men should have square, angular, and rugged teeth emerged. They also try to apply similar methodology to personality and age.

Kokich et $\mathrm{al}^{7}$ used variations of smile esthetics created using a computer-based approach and found that orthodontist, general dentists, and lay people had varying levels at which they detected dental discrepancies. A summary of his findings is included in Figure 1.

From its beginning, the primary goal of orthodontics has been the development of a well balanced face; however, most orthodontic analyses have typically examined the face from a lateral view. It has essentially been implied that if the lateral components of the face are well balanced, the frontal aspects will naturally become well balanced. Nothing could be further from the truth! Mackley ${ }^{33}$ showed that a profile photograph is not a reliable source of information to determine what a smile will look like.

Many of the previous studies of esthetics tend to focus on the teeth and the periodontium. However, within the field of dentistry, and specifically orthodontics, a new paradigm is considered to be emerging, namely the soft tissue paradigm. It calls for treatment planning not to be solely focused on the teeth, but also their arrangement to soft 
tissues. In fact, it suggests that the primary emphasis should be on facial and dental esthetics as a starting point for treatment goals if they are in concert with the patient's concerns and priorities as long as this approach does not compromise function and stability. One can establish a hierarchy of esthetic issues in this format.

"(1) the face in all three planes of space (macro-esthetics). Examples of problems that would be noted in that first step would be asymmetry, excessive or deficient face height, mandibular deficiency or excess, etc.

(2) the smile framework (mini-esthetics). The smile framework is bordered by the upper and lower lips on smile animation and includes such assessments as excessive gingival display on smile, inadequate gingival display, inappropriate gingival heights, and excessive buccal corridors.

(3) the teeth (micro-esthetics). This includes assessment of tooth proportions in height and width, gingival shape and contour, connectors and embrasures, black triangular holes, and tooth shade." 34

Two aspects of the mini-esthetics have recently captured the imagination of clinicians: smile arc and buccal corridor space. This is probably the case because they are within the realm of orthodontic treatment control, and they can easily be related to other concepts of orthodontic diagnosis and treatment such as arch form and width, gnathalogic concepts of occlusal function, and the extraction/ nonextraction controversy. Sarver ${ }^{35}$ recently focused his treatment and research on obtaining the ideal smile arc. According to Sarver, the ideal smile arc has the maxillary incisal edges describe a 
curvature parallel with the curvature of the lower lip. Although marketed as a new concept in treatment planning, the idea has been actually present for many years. Frush and Fisher ${ }^{36}$ were some of the first to publish this concept. Sarver advocates that the smile arc can be modified by headgear, bracket positioning, and in some cases orthognathic surgery.

Hulsey ${ }^{37}$ was one of the first to quantify the smile arc as a ratio to the lower lip. He used the ratio of the length of the perpendicular for the arc of the upper incisors to the length of the perpendicular arc of the lower lip. A perfect or ideal ratio equaled one. The limitation of this measurement was that it only took into account the curvature of the upper incisors and not the remaining dentition and was in fact more of a triangulation of the geometry than an arc.. The results of his study showed that orthodontically treated patients had lower smile scores than those that had not been treated (i.e. a flatter smile arc). He found the smile arc to be an important contributing factor to an attractive smile and suggested that orthodontics affected the smile arc, and thus determined how attractive a smile was judged.

Another concept originally attributed to Frush and Fisher is the presence of buccal corridor spaces. By definition, buccal corridor spaces are the negative space created between the buccal surfaces of the posterior teeth and the inner wall of the cheek. This is a concept that has been emphasized for years in denture esthetics - that is, having the appropriate amount of buccal corridor visible. Too much buccal corridor results in large empty spaces, while too little looks artificial and was considered the essence of bad prosthetic denture esthetics. 
Hulsey found that buccal corridor spaces do not contribute significantly to smile esthetics. Like the smile arc, Hulsey also determined a ratio for buccal corridor spaces, which he defined as a ratio between the lateral most points of the canines to the distance between the corners of the mouth. A limitation of this approach was that it only defined geometry of the canines to the corners of the mouth - these are not actual representative of negative buccal corridor space because other teeth can be visible in this space with the true corridor the space between these teeth and the inner check.

Computer simulations of buccal corridor spaces have been studied and validate Hulsey's original findings. Roden-Johnson et $\mathrm{al}^{38}$ modified cropped smiles with three different archforms to display absent and large buccal corridor spaces, which were then rated on a visual analog scale. He concluded that orthodontists, general dentists, and laypeople each evaluate smiles differently. Orthodontists preferred normal to broad arch forms over untreated arch forms, while lay people demonstrated no preference between treated and untreated arch forms. More significantly, it was concluded that buccal corridor spaces did not have an effect on the smile ratings of orthodontists, general dentists, and lay people.

In contrast, Moore et al ${ }^{39}$ recently found that laypersons could differentiate between different percentages of buccal corridor. When laypersons were shown full face color photographs with five alterations in buccal corridor, they preferred faces with minimal buccal corridor spaces. The laypersons were able to distinguish changes in buccal corridor on all levels except when they became minimal. Laypersons preferred broad smiles significantly more than narrow smiles. 
Some orthodontists currently advocate maxillary expansion in the absence of crossbites in an attempt to reduce buccal corridor space. ${ }^{40}$ Others have recommended non-extraction treatment in an effort to maintain arch width, therefore not increasing buccal corridor spaces. One of the first to examine this idea was Johnson and Smith. ${ }^{41}$ They found that there were no differences in smile esthetics between extraction and nonextraction cases. Recent studies by Gianelly and $\mathrm{Kim}^{42,43}$ show that premolar extraction does not result in narrower arch widths, nor does it alter perceptions of smile esthetics.

\section{Statement of the problem}

With the focus currently on facial and dental esthetics more direction appears to be required in order to validate and apply the partially tested philosophy of the esthetic paradigm. Although practitioners may prefer certain facial and dental relationships, these affinities must be considered in the context of patient preferences. Further, preferred and near preferred relationships may encompass a large range of acceptable relationships.

Until recently, research has been limited in this area because of the practical limitation of holding certain variables of the smile constant while manipulating and quantifying the changes of others. Advances in computer technology now make this possible. This study will begin to quantify and further refine practitioner and patient preferences for smile arcs and buccal corridors and their interactions. It will also evaluate the range of acceptability related to these variables 
The purpose of this study was to evaluate the effects of changes in smile arcs and buccal corridors, and interactions on the perceptions of smile esthetics as it relates to orthodontists versus a lay population.

\section{Specific Aims}

1. Develop a digital model that can be manipulated in a quantifiable manner to present the variables of interest (i.e., smile arcs and buccal corridors) to orthodontists and laymen;

2. Quantitatively evaluate the effects of changes in smile arcs and buccal corridors and combinations thereof using the digital model on the perceptions of smile esthetics as judged by a sample of orthodontists and laymen via a web based survey;

3. Assess the effects of changes in smile arcs and buccal corridors and combinations thereof on the perceptions of smile esthetics acceptability as judged by a sample of orthodontists and laymen via a web based survey;

4. Determine the possible effects of orthodontists and laymen characteristics on the variables related to the esthetics of the smile.

\section{Null Hypotheses}

$\mathrm{H}_{\mathrm{o} 1}$ : Rater type, rater gender, lip model gender, buccal corridor variations, smile arc variations, and combinations of variations thereof have no effect on the value a rater places on smile esthetics when measured using a visual analog scale (VAS). 
$\mathrm{H}_{02}$ : Rater type, rater gender, lip model gender, buccal corridor variations, smile arc variations, and combinations of variations thereof have no effect on the acceptability of appearance when measured using a dichotomous scale.

\section{References}

1. Ackerman JL, Proffit WR, Sarver DM. The emerging soft tissue paradigm in orthodontic diagnosis and treatment planning. Clin Orthod Res. May 1999;2(2):49-52.

2. Angle E. Malocclusion of the Teeth. 7 ed. Philadelphia: SS White Dental Mfg Co; 1907.

3. Lombardi RE. The principles of visual perception and their clinical application to denture esthetics. J Prosthet Dent. Apr 1973;29(4):358-382.

4. Morley J, Eubank J. Macroesthetic elements of smile design. J Am Dent Assoc. Jan 2001;132(1):39-45.

5. Tjan AH, Miller GD, The JG. Some esthetic factors in a smile. J Prosthet Dent. Jan 1984;51(1):24-28.

6. Sarver DM, Ackerman JL. Orthodontics about face: the re-emergence of the esthetic paradigm. Am J Orthod Dentofacial Orthop. May 2000;117(5):575-576.

7. Kokich VO, Jr., Kiyak HA, Shapiro PA. Comparing the perception of dentists and lay people to altered dental esthetics. J Esthet Dent. 1999;11(6):311-324.

8. Rosenstiel SF, Rashid RG. Public preferences for anterior tooth variations: a webbased study. $J$ Esthet Restor Dent. 2002;14(2):97-106.

9. Rosenstiel SF, Ward DH, Rashid RG. Dentists' preferences of anterior tooth proportion--a web-based study. J Prosthodont. Sep 2000;9(3):123-136.

10. Carnegie D. How to win friends and influence people. New York,: Simon and Schuster; 1936.

11. Shaw WC, Humphreys S. Influence of children's dentofacial appearance on teacher expectations. Community Dent Oral Epidemiol. Dec 1982;10(6):313-319.

12. Baldwin DC. Appearance and aesthetics in oral health. Community Dent Oral Epidemiol. 1980;8(5):244-256. 
13. Jenny J, Proshek JM. Visibility and prestige of occupations and the importance of dental appearance. J Can Dent Assoc. Dec 1986;52(12):987-989.

14. Graber LW, Lucker GW. Dental esthetic self-evaluation and satisfaction. Am J Orthod. Feb 1980;77(2):163-173.

15. Levinson NA. Psychologic facets of esthetic dental health care: a developmental perspective. J Prosthet Dent. Oct 1990;64(4):486-491.

16. Shaw WC. The influence of children's dentofacial appearance on their social attractiveness as judged by peers and lay adults. Am J Orthod. Apr 1981;79(4):399-415.

17. Byrne D, London O, Reeves K. The effects of physical attractiveness, sex, and attitude similarity on interpersonal attraction. Journal of Personality. 1968;36(2):259271.

18. Kleck RE, Rubenstein C. Physical attractiveness, perceived attitude similarity, and interpersonal attraction in an opposite-sex encounter. Journal of Personality \& Social Psychology. 1975;31(1):107-114.

19. Perrin FAC. Physical Attractiveness and Repulsiveness. Journal of Experimental Psychology. 1921;4:203-217.

20. Walster E, Aronson V, Abrahams D, Rottmann L. Importance of physical attractiveness in dating behavior. Journal of Personality \& Social Psychology. 1966;4(5):508-516.

21. Cleffore M, Salster E. The effect of physical attractiveness on teacher expectations. Soc Educ. 1973(46):248-258.

22. Dion K, Berscheid E, Walster E. What is beautiful is good. Journal of Personality \& Social Psychology. 1972; Vol. 24(3):285-290.

23. Miller AG. Role of physical attractiveness in impression formation. Psychonomic Science. 1970;19(4):241-243.

24. Brislin R, Lewis S. Dating and Physical Attractiveness: Replication. Psychological Reports. 1968;22(3, Pt. 1):976.

25. Huston TL. Ambiguity of acceptance, social desirability, and dating choice. Journal of Experimental Social Psychology. 1973;Vol. 9(1):32-42.

26. Peck S, Peck L, Kataja M. The gingival smile line. Angle Orthod. Summer 1992;62(2):91-100; discussion 101-102. 
27. Nakajima E MT, Yanagasawa M. The Japanese sense of beauty and facial proportions. II. The beautiful face and the $2^{1 / 2}$ rule. Quintescence International. 1985(9):629-637.

28. Ricketts RM. Divine proportion in facial esthetics. Clin Plast Surg. Oct 1982;9(4):401-422.

29. Ricketts RM. The biologic significance of the divine proportion and Fibonacci series. Am J Orthod. May 1982;81(5):351-370.

30. Preston JD. The golden proportion revisited. J Esthet Dent. 1993;5(6):247-251.

31. Shaw WC, Rees G, Dawe M, Charles CR. The influence of dentofacial appearance on the social attractiveness of young adults. Am J Orthod. Jan 1985;87(1):2126.

32. Frush JP, Fisher RD. Introduction to dentogenic restorations. J Prosthet Dent. 1955;5:586-595.

33. Mackley RJ. An evaluation of smiles before and after orthodontic treatment. Angle Orthod. Fall 1993;63(3):183-189; discussion 190.

34. Proffit WR, Fields HW, Sarver DM. Contemporary orthodontics. 4th ed. St. Louis: Mosby; 2006.

35. Sarver DM. The importance of incisor positioning in the esthetic smile: the smile arc. Am J Orthod Dentofacial Orthop. Aug 2001;120(2):98-111.

36. Frush JP, Fisher RD. The Dynesthetic Interpretation of the Dentogenic Concept. $J$ Prosthet Dent. 1958;8:558.

37. Hulsey CM. An esthetic evaluation of lip-teeth relationships present in the smile. Am J Orthod. Feb 1970;57(2):132-144.

38. Roden-Johnson D. The Effects of Buccal Corridor Spaces and Arch Form as Related to Smile Esthetics. Houston: Orthodontics, University of Texas Health Science Center at Houston, Dental Branch; 2003.

39. Moore T, Southard KA, Casko JS, Qian F, Southard TE. Buccal corridors and smile esthetics. Am J Orthod Dentofacial Orthop. Feb 2005;127(2):208-213.

40. McNamara JA. Maxillary transverse deficiency. Am J Orthod Dentofacial Orthop. May 2000;117(5):567-570.

41. Johnson DK, Smith RJ. Smile esthetics after orthodontic treatment with and without extraction of four first premolars. Am J Orthod Dentofacial Orthop. Aug 1995;108(2):162-167. 
42. Gianelly AA. Arch width after extraction and nonextraction treatment. Am $J$ Orthod Dentofacial Orthop. Jan 2003;123(1):25-28.

43. Kim E, Gianelly AA. Extraction vs nonextraction: arch widths and smile esthetics. Angle Orthod. Aug 2003;73(4):354-358. 


\section{CHAPTER 2}

\section{MATERIALS AND METHODS}

The approach used in this research was to present experienced orthodontists with digital images of male and female smiles so they could manually adjust the smile arc and buccal corridors to match criteria we requested. Later, these data were used to create a group of standard images ( 9 male and 9 female) that demonstrated the medians of the categories of smile arc and buccal corridors for rating by a larger group of both orthodontists and laypersons.

\section{Model Selection}

A digital archive was examined to obtain one frontal intraoral photograph of ideally aligned teeth, and one extraoral photograph that displayed esthetic lips. The high resolution photographs were from different female patients.

\section{Image Manipulation}

The original JPEG images were opened in Adobe Photoshop ${ }^{\circledR} 7.0$ and saved as a Photoshop ${ }^{\circledR}$ Document (PSD) so that subsequent file saves would not result in image degradation. The images of the teeth were cropped to display only the right side of the 
mouth, and then mirrored to create a symmetrical image. Care was taken to insure the incisal edges of the teeth were maintained on a horizontal. A final crop removed any evidence of lip retractors and showed a relatively flat smile arc and supporting periodontal structures. The images of the lips were cropped to only show the lips with minimal surrounding tissue. No other facial features were evident.

Using the imaging program, the teeth and periodontium were erased from the picture to create a "hollow" set of lips. Once again, care was taken to insure the corners of the mouth remained horizontal. In order to create a "male" set of lips, a black and white gradient pattern overlay was used to create typical facial hair. This allowed the male lips to have identical shape and color characteristics to the female lips, while appearing more masculine.

Next, Math GVTM FREEWARE Version 3.1 was used to create a sequence of parabolic forms. Using the function $\mathrm{f}(\mathrm{x})=\mathrm{ax}^{2}$, with " $\mathrm{a}$ " representing a coefficient ranging from $0.01-0.12$, a series of parabolas, numbered $1-12$, respectively of increasing curvature were plotted. This plot was saved as a BMP for use in Adobe Photoshop ${ }^{\mathrm{TM}}$ 7.0. This image was then stretched to fit the number 7 parabola $(a=0.07)$ to the curvature of the lower lip in the lip image. The edges of the lip were then adjusted to perfectly match the number 7 parabola, with the midline centered and the corners of the cheek equidistant from the midline.

The teeth were then sized to fit the lips so that the second molars would be located at the same horizontal distance to the corners of the mouth. These images were then morphed using a 3D transform function (Spherical Render) in Photoshop ${ }^{\mathrm{TM}}$. Beginning with the original flat teeth, the images were carefully morphed to make the incisal edges 
of the maxillary teeth fit the curves. With the 3D transformations there was some distortion among the teeth. While the vertical changes account for the changes in smile arc, horizontal changes played little to no role. After each transformation, the image was overlayed with the pre-morph image and resized to account for any distortion in the horizontal region that might have occurred in the maxillary incisor region, which kept distortions in the anterior region to a minimum. The morphing process was repeated on each subsequent image until a total of 12 smile arc variations were created, each matching its respective curve when completed.

All lips, morphs of the teeth, and smile arc template were stored as layers in Photoshop ${ }^{\mathrm{TM}}$ which allowed them to be overlayed upon each other. By selecting the lips and a set of teeth, a composite smile could be created.

To create the buccal corridor spaces, composite smile number 7 was chosen because this represented the ideal smile arc based on its current definition of the maxillary incisal edges parallel to the curvature of the lower lip. A black diffusing airbrush in Photoshop ${ }^{\circledR}$ was used to create shade layers and quantified in relation to the teeth as follows: none, buccal groove of 7 (BG7), mesial of 7 (M7), buccal groove of 6 (BG6), mesial of 6 (M6), mesial of 5 (M5), and mesial of 4 (M4), numbered 1-6 respectively. The location represents the extent to where the shadowing of the buccal corridor ends, not necessarily the most opaque portion of the shadowing.

Once the smile elements were completed, a composite smile was completed by combining a set of teeth and lips with buccal corridor and facial hair as needed. 


\section{Human Subjects Approval}

Applications for Institutional Review Board (IRB) exemption, HIPAA waiver, and Waiver of Written Informed Consent were made and granted by the The Ohio State University Biomedical Sciences Institutional Review Board.

\section{Pilot Study I}

A pilot survey was constructed using Quask ${ }^{\mathrm{TM}}$ Form Artist software, which allowed the creation of web based surveys. The purpose of the pilot study was to ask experienced orthodontists, who were defined as those finishing residency a minimum of five years prior, to set the standard for the ideal smile arc, the maximum acceptable accentuated smile arc, the moderate buccal corridor, and the large buccal corridor for male and female smiles. These data later were used to construct the main survey. Quask $^{\mathrm{TM}}$ Form Artist included the creation of emoticons, which are interactive sliding bars which display a changing picture when the slider is activated. Smile arcs 4-10 were used to create the ideal smile arc emoticon and smile arcs 7-12 were used to create the accentuated smile arc emoticon. Buccal corridors 1-6 were used for both moderate and large buccal corridor emoticons. Emoticons were created for both male and female smiles (Figure 3.1).

The survey asked the respondent for the following information - survey type (initial or follow up), the year of completion of residency and an email address so that a follow up reliability survey could be completed at least two weeks later. The orthodontists were given definitions of smile arcs and buccal corridors and asked to use the slider to make a choice of an ideal smile arc, an accentuated smile arc, an ideal buccal 
corridor and an excessive buccal corridor after exploring the full range of choices. The pilot survey was hosted on a web server. Orthodontists were then contacted by telephone or email from those listed in the American Association of Orthodontist Directory, to participate in the pilot study.

\section{Pilot Study II}

After examining the results of the pilot study, it was evident there was some confusion related to buccal corridors. Despite the definition provided, it was apparent some orthodontists incorrectly considered a large buccal corridor to mean a large display of teeth as opposed to an increased negative or dark space. Some orthodontists chose smaller buccal corridor displays for the large buccal corridor response than their moderate buccal corridor response. An independent group of orthodontists were asked to complete a modified version of the buccal corridor questions. In this survey, the orthodontists were asked to choose the ideal buccal corridor (i.e., the ideal amount of black space) and an excessive buccal corridor (i.e., too much black space) to eliminate the previous confusion of buccal corridors. The modified web-based pilot survey was hosted on a web server and follow up reliability survey was completed. An of the example of the actual survey and responses are included in the Appendix.

\section{Main Survey}

The main survey was then conducted using the standards set in the pilot surveys. The median and mode smile arc values from the first pilot study and buccal corridor 
values from the modified pilot survey responses, which were identical, were used to guide creation of images for the main study.

Flat smile arcs and the absence of buccal corridors were considered to be inherently defined. In order to establish an excessive smile arc, the number 11 smile arc was used because this was beyond the maximum acceptable level set by the orthodontists in the pilot survey. Combinations of the three smile arc variations (flat, ideal, excessive) and the buccal corridor variations (none, ideal, excessive) were used to create 9 female and 9 male images. The final female and male composite images are included in Figures 3.5 and 3.6 respectively.

The main survey was created using Quask ${ }^{\mathrm{TM}}$ Form Artist. In order to characterize the rater sample, respondents were asked to voluntarily provide demographic information which included gender, U.S. geographical region, ethnic background, highest level of education completed, and any dental affiliation. If the respondent was an orthodontist, general dentist, or other dental specialist, they were asked to enter the year they completed their professional training. If the respondent was a layperson, they were asked to choose their income bracket from a drop down list.

The respondents were then given specific instructions on how to complete the survey. For each image, the respondents were asked to rate the image on a visual analog scale (VAS) anchored with highly unattractive on the left, and highly attractive on the right. Visual cues in the form of a frowning face and a smiling face were included with the left and right anchors, respectively. Since resolution settings and computer monitor sizes affect the size of the visual analog scale, no specific length of VAS was used. The visual analog scale was 345 pixels long, with the size of the survey being 800 pixels wide 
by 500 pixels high, and the image being 400 pixels wide by 179 pixels high. An example of a question from the main survey is presented in Figure 3.7.

Raters were asked to evaluate the 9 female and 9 male smiles twice in order to determine reliability for a total of 36 smiles. The survey was designed such that the 36 smiles were randomized each time the survey was taken. In order to submit the survey, the software verified that both questions for all 36 smiles had been completed. An incomplete survey would return the respondent to the unanswered question and would flash the question three times.

The main survey was hosted on a web server. Orthodontists were contacted in person, by telephone, or email through information obtained in the American Association of Orthodontists Member Directory and asked to participate. Available laypersons were contacted in person, by telephone, or email but with conscious effort not to include those with any dental affiliations. All respondents were asked to confirm that they were over 18 years of age and reassured that participation was voluntary and confidential.

\section{Statistical Analysis}

Reliability for the pilot surveys and the attractiveness portion of the main survey was tested using the intra-class correlation coefficient (ICC) with $95 \%$ confidence interval. Differences in attractiveness ratings were analyzed using a factorial analysis of variance with repeated measures. Post hoc testing was done using the Tukey-Kramer method. The level of significance was set at a $p$ value of $<0.05$ for all analyses.

For an experiment-wise, non-directional alpha risk of 0.05 and assuming a common standard deviation of $17.42^{1}$ a sample size of 90 subjects per rater group was 
necessary to achieve a power of 0.85 to demonstrate a difference of $\pm 10 \%$ on the visual analogue scale.

\section{References}

1. Maple J, Vig K, Beck FM, Larsen P, Shanker S. A comparison of providers and consumers' perception of facial profile attractiveness [Master's]. Columbus: Section of Orthodontics, The Ohio State University; 2003. 


\title{
CHAPTER 3
}

\section{MANUSCRIPT:}

\section{The Attractiveness of Variations in Smile Arc and Buccal Corridor Space as Judged by Orthodontists and Laymen}

\begin{abstract}
Some believe orthodontics has undergone a "paradigm shift" to focus more on esthetics, with emphasis on the soft tissues surrounding the mouth. This web based study evaluated changes in attractiveness based on computerized variations of smile arcs and buccal corridors for male and female smiles judged by orthodontists and laypersons on a visual analog scale. The results indicate that both laypersons and orthodontists prefer smiles in which the smile arc parallels the lower lip and buccal corridors are minimal. Significantly lower attractiveness ratings were found for smiles with flat smile arcs and excessive buccal corridors. Flattening of the smile arc overwhelms the deleterious effects of excessive buccal corridors on attractiveness ratings. Based on the results of this study, care should be taken not to produce an excessively flat smile arc during orthodontic treatment.
\end{abstract}




\section{INTRODUCTION}

Most orthodontists understand the attainment of optimal esthetics is complex and involves the relationship of the teeth to both intraoral and extraoral soft tissues.

Two aspects of the smile esthetics, smile arc and buccal corridor space, recently captured the imagination of clinicians in spite of little scientific evidence. ${ }^{1}$

Sarver ${ }^{2}$ recently focused his treatment planning on obtaining the ideal smile arc described by the curvature of the maxillary incisal edges being parallel to the curvature of

the lower lip, which is similar to Frush and Fisher's concept. ${ }^{3}$ Hulsey ${ }^{4}$ was one of the first to quantify the smile arc and the results of his study showed that orthodontically treated patients had lower smile ratios (flatter) than untreated patients.

Another concept originally attributed to Frush and Fisher ${ }^{3}$ was the presence of buccal corridor spaces, the negative space created between the buccal surfaces of the posterior teeth and the inner wall of the cheek. Hulsey ${ }^{4}$ found that buccal corridor spaces did not contribute significantly to smile esthetics.

Studying smile esthetics was difficult in the past due to the inability to standardize a realistic model and alter the variables of interest. With the evolution of digital imaging, however, manipulation of the variables could be accomplished in a reliable and quantifiable manner. Sarver and Ackerman ${ }^{5}$ and others, ${ }^{6}$ using computer simulation, have applied this methodology to smiles.

Roden-Johnson et al, ${ }^{7}$ using computer simulations of buccal corridors spaces, validated Hulsey's original findings using smiles with three different archforms to display absent and large buccal corridor spaces, which were then rated on a visual analog 
scale (VAS). Orthodontists preferred normal to broad arch forms over untreated, narrower arch forms, while lay people demonstrated no preference between treated and untreated arch forms. More significantly, buccal corridor spaces did not have an effect on the smile ratings of orthodontists, general dentists, and lay people.

By contrast, Moore et $\mathrm{al}^{8}$ recently found that laypersons could differentiate between different percentages of buccal corridor space. When shown full face color photographs with five alterations in buccal corridor, laypersons preferred faces with minimal buccal corridor spaces. Laypersons preferred broad smiles significantly more than narrow smiles and were able to distinguish changes in buccal corridor except when they became minimal.

The purpose of this study was to evaluate, using digital manipulated images and an internet study, the effects of changes in smile arcs and buccal corridors and their interactions on the perceptions of smile attractiveness as judged by orthodontists and lay raters.

\section{MATERIALS AND METHODS}

\section{Image Manipulation}

After IRB approval, a digital archive was examined to obtain one frontal intraoral photograph of ideally aligned teeth, and one extraoral photograph that displayed esthetic lips from different patients. These images were modified using Adobe Photoshop ${ }^{\circledR} 7.0$ (San Jose, California) to create a bilaterally symmetric set of teeth and a set of lips without evidence of teeth and periodontium. The set of teeth were morphed using a 3-D spherical render function to modify the curvature of the incisal edges to fit twelve curves ranging from flat to accentuated based on sequentially increasing parabolic arcs, 
numbered 1-12 respectively. The lips were modified such that the lower lip would coincide with the number 7 curve.

The number 7 smile arc and lips were combined to form the ideal composite smile with all teeth displayed to the maxillary second molar. A black diffusing airbrush was used to create seven different sizes of buccal corridor quantified in relation to the teeth, numbered 1-6.

In order to create a "male" set of lips, a black gradient pattern overlay was used to create typical facial hair. A composite smile could then be completed by combining a set of teeth and lips with buccal corridor and facial hair as needed.

\section{Pilot Survey}

Pilot surveys were administered to experienced orthodontists (at least five years post residency) in order to set the standards for the ideal smile arc, the maximum acceptable accentuated smile arc, the ideal buccal corridor (i.e., the ideal amount of black space) and an excessive buccal corridor (i.e., too much black space). Quask ${ }^{\mathrm{TM}}$ Form Artist (New Canaan, Connecticut) was used to author the web survey and allowed the creation of emoticons, which are interactive sliding bars that display a changing picture when the slider is activated. One emoticon displayed smile arcs, another buccal corridors.

Orthodontists listed in the American Association of Orthodontists (AAO) Directory were contacted to participate in the pilot survey. The survey asked the rater for the year of completion of residency and an email address so that a follow up reliability survey could be completed at least two weeks later. The orthodontists were given written definitions of smile arcs and buccal corridors and asked to use the slider to set the visual 
standards for smile arc and buccal corridor variations for male and female smiles. Figure 3.1 illustrates an example question, available choices, and responses from the pilot survey.

\section{Main Survey}

Median values from the pilot survey were used to create images for the main study. Flat smile arcs and absent buccal corridors were considered to be inherently defined. The number 11 smile arc established the excessive smile arc because this was beyond the maximum acceptable level initially set by the orthodontists. Combinations of the three smile arc variations (flat, ideal, excessive) and the buccal corridor variations (none, ideal, excessive) were used to create 9 female and 9 male images. Figure 3.2 illustrates the 9 composite female smiles.

The main survey was created using Quask ${ }^{\mathrm{TM}}$ Form Artist. Different orthodontists were invited to participate. Available laypersons were contacted with conscious effort not to include those with dental affiliations.

Raters voluntarily provided demographic information including gender, U.S. geographical region, ethnic background, highest level of education completed, and any dental affiliation. Orthodontists were asked for the year they completed their professional training. If the rater was a layperson, they were asked to choose their income bracket from a drop down list.

The raters rated each image on a VAS anchored with highly unattractive on the left, and highly attractive on the right. Visual cues were also included. Since resolution 
settings and computer monitor sizes affect the size of the VAS, the rating was based on a percentage of the line length in pixels.

Raters were asked to evaluate the 9 female and 9 male smiles twice in order to determine reliability for a total of 36 smiles. The survey was designed such that the 36 smiles were randomized each time the survey was taken

\section{Statistical Analysis}

Reliability for the pilot surveys and the attractiveness portion of the main survey was tested using the intra-class correlation coefficient (ICC) with a 95\% confidence interval. The mean scores from both attractiveness ratings were adjusted using the least means squared method. Differences in attractiveness ratings were analyzed using a factorial analysis of variance (ANOVA) with repeated measures. Post hoc testing was done using the Tukey-Kramer method. The level of significance was set at a $\mathrm{p}<0.05$.

For an experiment-wise, non-directional alpha risk of 0.05 and assuming a common standard deviation of $17.42,{ }^{9}$ a sample size of 90 per rater group was necessary to achieve a power of 0.85 to demonstrate a difference of $\pm 10 \%$ on the VAS.

\section{RESULTS}

\section{Rater Demographics}

A total of 40 orthodontists participated in the first pilot survey. For the main survey responses, 115 were laypersons and 131 orthodontists. On average, orthodontists were 22 years post residency. The majority of laypeople were college educated, Caucasian and from the central US with a median income of $\$ 50,000$ to $\$ 75,000$. 


\section{Reliability}

For the pilot surveys, the overall ICC (with 95\% confidence interval) was 0.94(0.91-0.95), which was excellent. For attractiveness, the overall ICC for rating the same picture twice in the main study was $0.87(0.83-0.91)$ with laypersons and orthodontists showing excellent reliability of $[\mathrm{ICC}=0.91(0.89-0.93)]$ and $[\mathrm{ICC}=$ $0.81(0.77-0.85)]$, respectively.

\section{Clinical Significance versus Statistical Significance}

Limited data exist to define a clinically significant difference on a VAS for dental attractiveness. The VAS has been validated for pain research and generally a minimum clinically significant difference ranges from 9 to $13 \mathrm{~mm}$ on a $100 \mathrm{~mm}$ VAS. ${ }^{10-14}$ Although it is not known whether this difference translates to attractiveness, this study set a conservative and arbitrary benchmark of a 15\% VAS difference as clinically significant.

\section{Attractiveness}

As determined by the ANOVA, all significant effects may be addressed through the following two interactions: Model Gender by Buccal Corridor by Smile Arc and Rater Gender by Group by Buccal Corridor by Smile Arc.

\section{Model Gender by Buccal Corridor by Smile Arc}

Figure 3.3 illustrates the attractiveness ratings of the nine composite images of buccal corridor and smile arc variations based on whether the model was male or female. The higher the rating, the more attractive the smile was perceived. 
For attractiveness and the gender of the model, the following general findings were noted. Attractiveness scores for all smile arcs with absent and ideal buccal corridors were nearly identical for males and females, while excessive buccal corridors brought all ratings down. For both genders flat smile arcs overwhelmed the attractiveness of all buccal corridors and were rated in the lower $40 \%$ of the scale.

Regardless of gender, for all buccal corridors the raters significantly preferred the ideal and excessive smile arcs over the flat smile arcs. Buccal corridor size made a significant difference only when the smile arc was ideal for males. For females, all buccal corridor widths with ideal and excessive smile arcs were found to be in the upper half of the attractiveness scale. This was true for males except when the buccal corridors became excessive.

\section{Rater Gender by Group by Buccal Corridor by Smile Arc}

Figure 3.4 illustrates the attractiveness ratings of male and female laypersons and orthodontists on the nine composite images of buccal corridor and smile arc variations.

The following general observations were noted. Orthodontists, especially female orthodontists, used a greater range of the rating instrument than laypersons. Buccal corridors and smile arcs generally made less difference to laypersons than to orthodontists. All raters, regardless of buccal corridors, generally preferred ideal smile arcs over excessive smile arc and excessive smile arcs over flat smile arcs.

Specific findings included, all raters regardless of buccal corridor rated ideal smile arcs significantly more attractive than flat smile arcs. All orthodontists, regardless of buccal corridors rated the excessive smile arc significantly more attractive than the flat 
smile arc. With all buccal corridors, the orthodontists rated the flat smile arc lower than the laypersons. There were no significant differences between male and female laypersons or orthodontists for any ratings.

\section{DISCUSSION}

\section{Data Collection Methods}

The results of the sliding emoticons used in the pilot indicated this was a highly reliable method for studying smile esthetics. An ICC of 0.94 with a two week wash out period was an excellent result.

Recently, the VAS gained popularity for measuring subtle differences in dental and facial attractiveness. ${ }^{6,9,15-24}$ In the evaluation of dental attractiveness, moderately high correlation coefficients for reliability $(0.87)$ have been reported with the use of the VAS. $^{25}$

In this study, the VAS allowed a simple and rapid method for raters to indicate their perceptions of attractiveness using a continuous range of choices and did not restrict raters to categories as in a Likert scale. As a limitation, the scale may mean different things to different raters, all responses may not be equal, ${ }^{26}$ and raters will use different portions of the scale and ignore others -- particularly the extremes. ${ }^{21}$ To address these limitations, this study used an adjusted mean to compare ratings across groups.

A web based survey introduced a potential bias because it was limited to raters with internet computer access. Based on the demographic data, the lay population appears to have a slightly higher socioeconomic status than the general population (household income of $\$ 43,318^{27}$ ). These biases should be considered when generalizing the results. 


\begin{abstract}
Attractiveness
This study examined attractiveness depending upon the smile arc and the buccal corridor because there were possible interactions. The gender of the model only demonstrated importance when the smile arc was ideal and the buccal corridor excessive (Figure 3.3). Under those conditions, the male was viewed as more unattractive, perhaps because the excessive buccal corridor set by the pilot study was much larger than for the females.

Although female orthodontists used more of the rating scale than others, and they detected significant differences between some categories male orthodontists did not, there were no significant differences between genders for either orthodontists or laypersons (Figure 3.4). Although no other studies have reported differences between male and female orthodontists, some studies have shown that females tend to rate attractiveness higher than their male counterparts ${ }^{28,29}$ and laypersons have been reported to be less critical than orthodontists ${ }^{30}$ when rating profiles.
\end{abstract}

\title{
Comparison to Previous Research
}

As mentioned previously, Hulsey ${ }^{4}$ found ideal smile arcs had higher smile scores and buccal corridors did not affect smile scores. The findings of this study agree with Hulsey's regarding smile arc, and partially agree regarding buccal corridors. A flat smile arc will significantly reduce the attractiveness of any male or female smile regardless of the buccal corridor size. The raters in the present study found no differences in buccal 
corridor except when they became excessively large and the smile arc was ideal. It is possible that the Hulsey's buccal corridors were not large enough to elicit a negative response.

Yoon et $\mathrm{al}^{31}$ performed a similar study in the Korea and found higher esthetic scores for ideal smile arcs as well as for smiles which displayed a greater number of teeth. This is in agreement with the present study.

Two recent studies looked at the effect of buccal corridor on smile esthetics using digital manipulation. Roden-Johnson et $\mathrm{al}^{16}$ found no difference in female smiles with and without buccal corridors when judged by orthodontists, general dentists, and laypersons. This contrasts the results of the present study for buccal corridors, where orthodontists detected some differences and laypersons did not. Roden-Johnson et al did not quantify buccal corridors - they were classified as present or absent. It is possible their buccal corridors did not meet the threshold for excessive buccal corridors determined by this study.

Moore et $\mathrm{al}^{8}$ found laypersons were able to distinguish differing levels of buccal corridor and preferred broader smiles with minimal buccal corridors. That study quantified buccal corridors as a percentage of total smile width and found no significant differences between medium-broad and broad buccal corridors. The present study agrees with Moore et al for analogous (based on percentage translation) minimal buccal corridors judged by laypersons, but they examined a greater range of corridor sizes. The current study found differences for male models when the smile arc was ideal. There were no differences for model gender in Moore et al. 
There were no differences for gender of lay raters in Moore et al or the present study. We also did not find differences between attractiveness ratings for male and female orthodontists, but female orthodontist did detect some differences not seen by male orthodontists.

The methods of Moore et al were distinctly different from this study. Moore et al used comparisons of one image to another where this study attempted to judge innate attractiveness on an anchored scale.

\section{CONCLUSIONS}

1. Excessive buccal corridors and flat smile arcs in both male and female smiles are rated as less attractive by both orthodontists and laypersons.

2. Flat smile arcs overwhelmingly decrease attractiveness ratings regardless of buccal corridor. 


\section{LEGEND}

Figure 3.1 illustrates an example of an emoticon, displayed images, and results from the pilot survey.

Figure 3.2 illlustrates the nine final composite female images presented in the main survey with alterations in smile arc and buccal corridor.

Figure 3.3 represents the interactions between model gender, buccal corridor, and smile arc. A difference of $15 \%$ or greater between variables was considered a clinically significant difference.

Figure 3.4 represents the interactions between rater gender, group, buccal corridor, and smile arc. A difference of $15 \%$ or greater between was considered a clinically significant difference. 


\section{FIGURES}

For the FEMALE smile below, what do you consider to be an IDEAL smile arc?

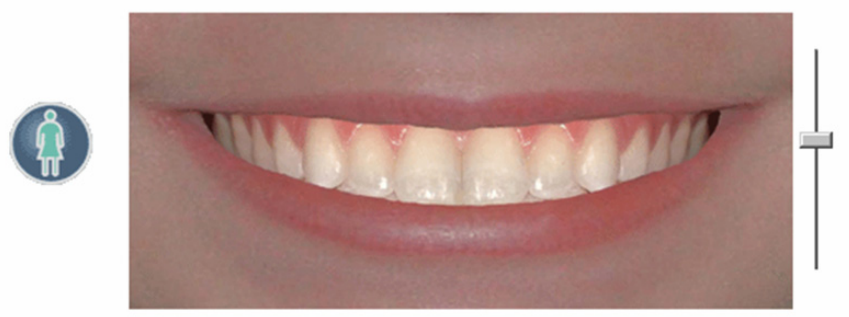

Use the slider on the right to adjust the curvature of the teeth.

First move the slider to the extreme to see the possible range of options, and then choose the appropriate position.

(1) Ideal SA Female $v$

Smile Arc Responses (Female and males were identical) Green $=$ Ideal, Red $=$ Accentuated
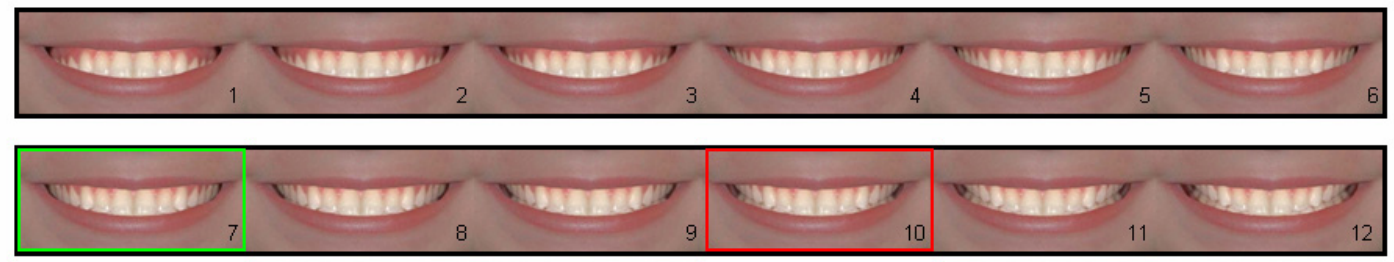

Buccal Corridor Responses (Female Model)

Green $=$ Ideal, Red $=$ Excessive

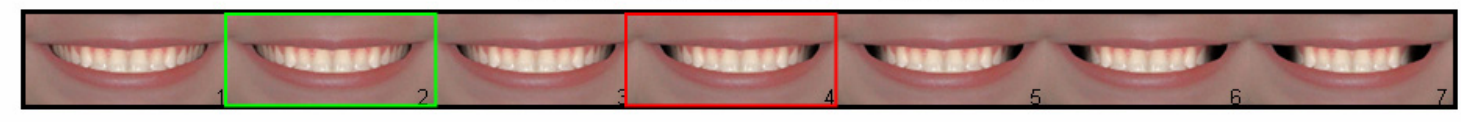

Buccal Corridor Responses (Male Model)

Green $=$ Ideal, Red $=$ Excessive

\begin{tabular}{|c|c|c|c|c|}
\hline 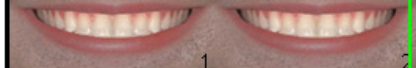 & vonntager & 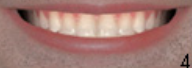 & Ponninge & Dounder vountor \\
\hline
\end{tabular}

Figure 3.1: Pilot Survey Example and Responses 


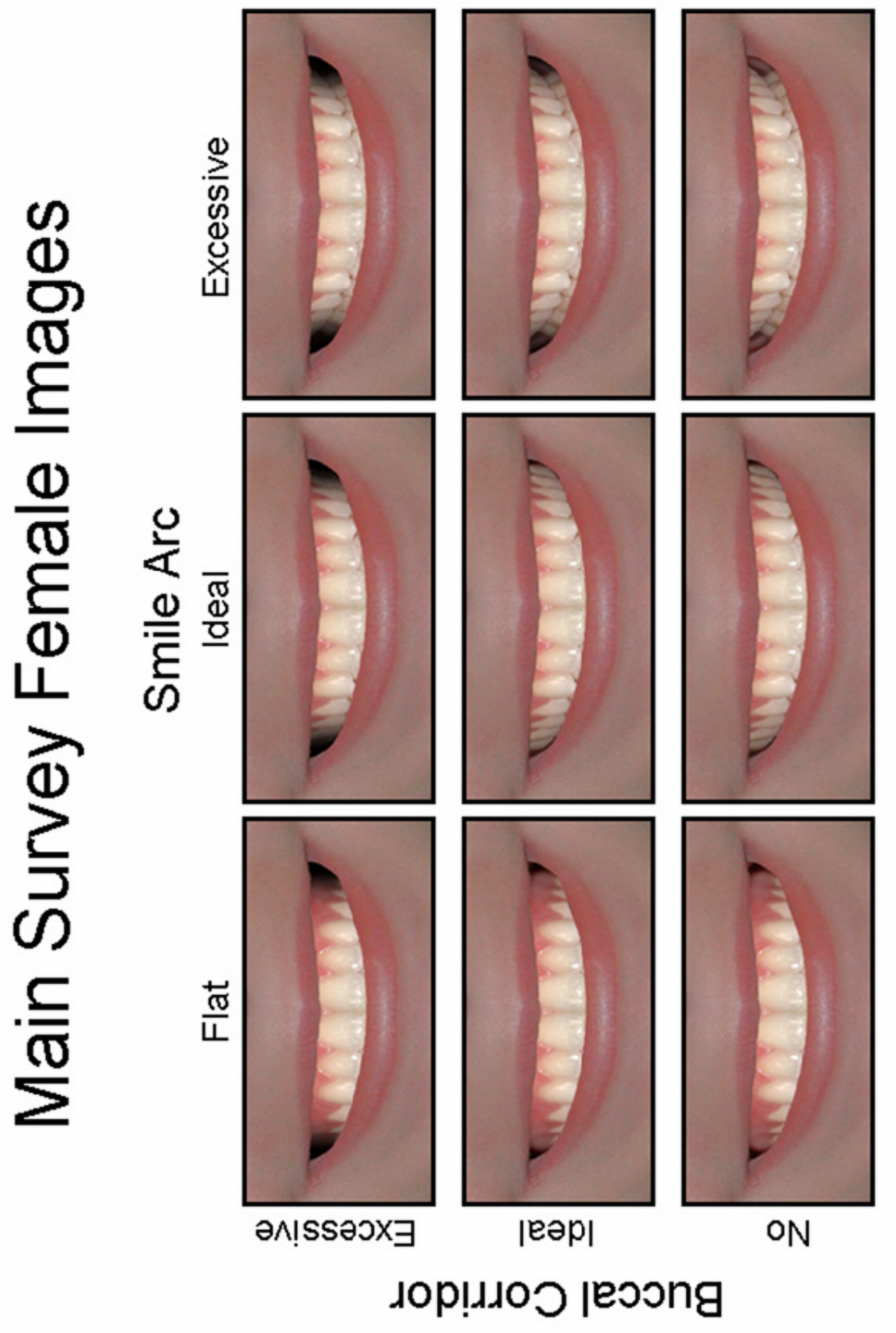

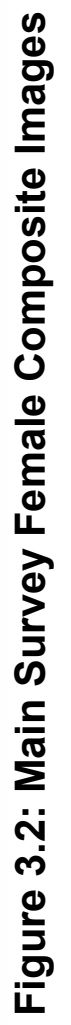




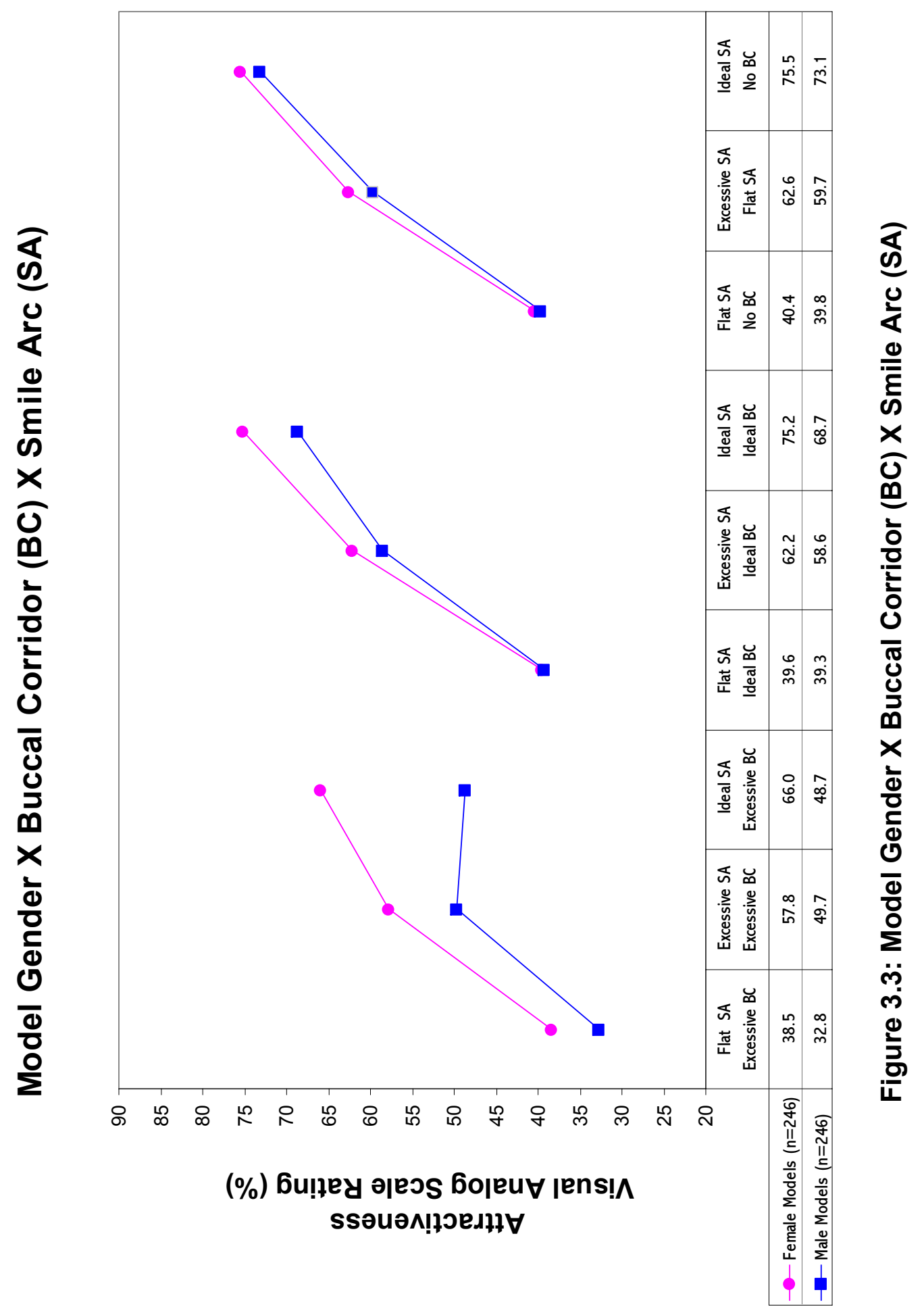




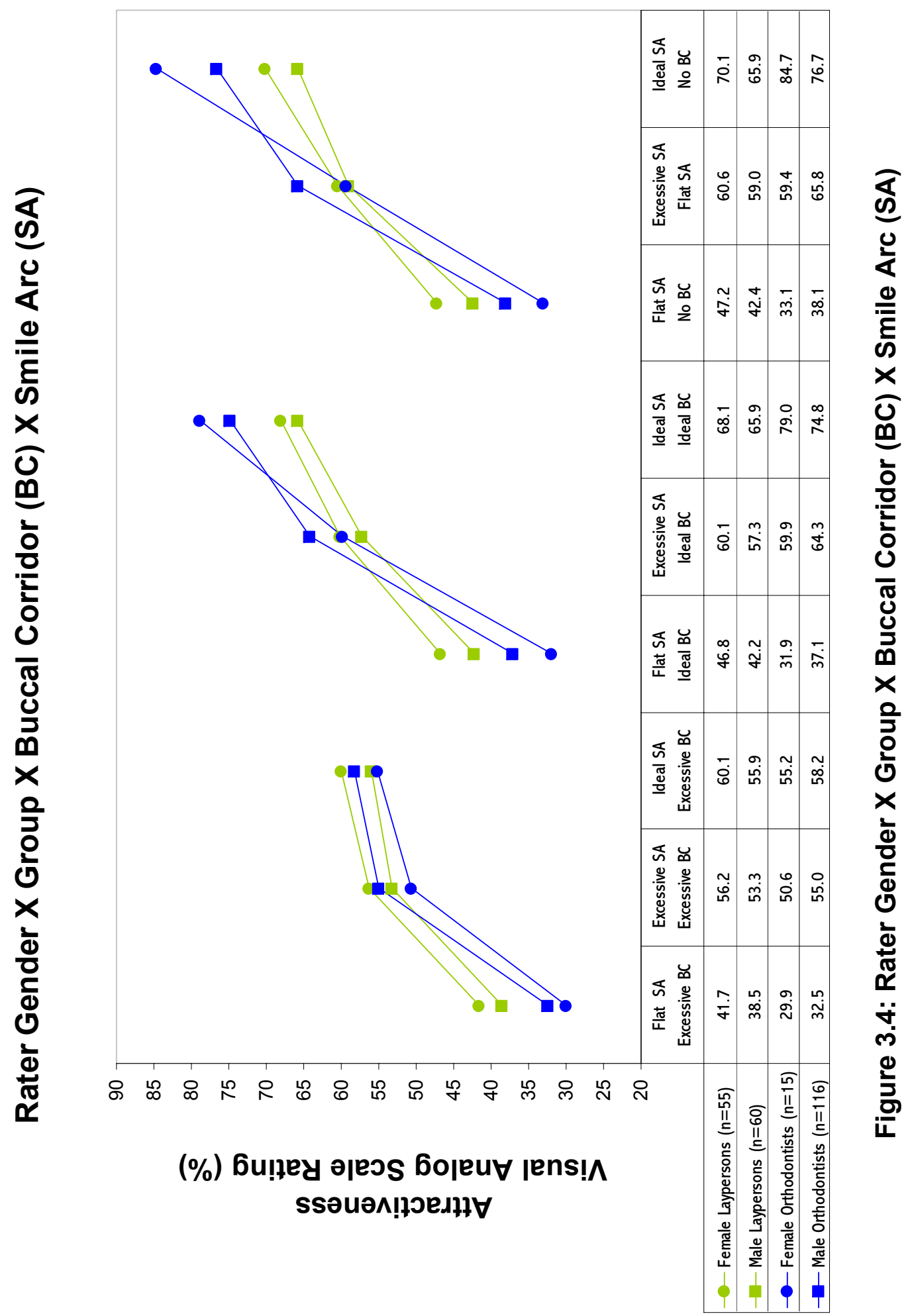




\section{REFERENCES}

1. Brislin R, Lewis S. Dating and Physical Attractiveness: Replication.

Psychological Reports. 1968;22(3, Pt. 1):976.

2. Sarver DM. The importance of incisor positioning in the esthetic smile: the smile arc. Am J Orthod Dentofacial Orthop. Aug 2001;120(2):98-111.

3. Frush JP, Fisher RD. The Dynesthetic Interpretation of the Dentogenic Concept. $J$ Prosthet Dent. 1958;8:558.

4. Hulsey CM. An esthetic evaluation of lip-teeth relationships present in the smile. Am J Orthod. Feb 1970;57(2):132-144.

5. Sarver DM, Ackerman JL. Orthodontics about face: the re-emergence of the esthetic paradigm. Am J Orthod Dentofacial Orthop. May 2000;117(5):575-576.

6. Kokich VO, Jr., Kiyak HA, Shapiro PA. Comparing the perception of dentists and lay people to altered dental esthetics. $J$ Esthet Dent. 1999;11(6):311-324.

7. Roden-Johnson D. The Effects of Buccal Corridor Spaces and Arch Form as Related to Smile Esthetics. Houston: Orthodontics, University of Texas Health Science Center at Houston, Dental Branch; 2003.

8. Moore T, Southard KA, Casko JS, Qian F, Southard TE. Buccal corridors and smile esthetics. Am J Orthod Dentofacial Orthop. Feb 2005;127(2):208-213.

9. Maple J, Vig K, Beck FM, Larsen P, Shanker S. A comparison of providers and consumers' perception of facial profile attractiveness [Master's]. Columbus: Section of Orthodontics, The Ohio State University; 2003.

10. Todd KH, Funk KG, Funk JP, Bonacci R. Clinical significance of reported changes in pain severity. Ann Emerg Med. Apr 1996;27(4):485-489.

11. Kelly AM. Does the clinically significant difference in visual analog scale pain scores vary with gender, age, or cause of pain? Acad Emerg Med. Nov 1998;5(11):10861090.

12. Powell CV, Kelly AM, Williams A. Determining the minimum clinically significant difference in visual analog pain score for children. Ann Emerg Med. Jan 2001;37(1):28-31.

13. Yamamoto LG, Nomura JT, Sato RL, Ahern RM, Snow JL, Kuwaye TT. Minimum clinically significant VAS differences for simultaneous (paired) interval serial pain assessments. Am J Emerg Med. May 2003;21(3):176-179. 
14. Zisapel N, Nir T. Determination of the minimal clinically significant difference on a patient visual analog sleep quality scale. J Sleep Res. Dec 2003;12(4):291-298.

15. Baker BW, Woods MG. The role of the divine proportion in the esthetic improvement of patients undergoing combined orthodontic/orthognathic surgical treatment. Int J Adult Orthodon Orthognath Surg. 2001;16(2):108-120.

16. Roden-Johnson D, Gallerno R, English J. The Effects of Buccal Corridor Spaces and Arch Form as Related to Smile Esthetics. Houston: Orthodontics, University of Texas Health Science Center at Houston, Dental Branch; 2003.

17. Levy SM, Warren JJ, Jakobsen JR. Follow-up study of dental students' esthetic perceptions of mild dental fluorosis. Community Dent Oral Epidemiol. Feb 2002;30(1):24-28.

18. Michiels G, Sather AH. Determinants of facial attractiveness in a sample of white women. Int J Adult Orthodon Orthognath Surg. 1994;9(2):95-103.

19. O'Neill K, Harkness M, Knight R. Ratings of profile attractiveness after functional appliance treatment. Am J Orthod Dentofacial Orthop. Oct 2000;118(4):371376; discussion 377.

20. Phillips C, Trentini CJ, Douvartzidis N. The effect of treatment on facial attractiveness. J Oral Maxillofac Surg. Jun 1992;50(6):590-594.

21. Phillips C, Tulloch C, Dann C. Rating of facial attractiveness. Community Dent Oral Epidemiol. Aug 1992;20(4):214-220.

22. Schlosser JB, Preston CB, Lampasso J. The effects of computer-aided anteroposterior maxillary incisor movement on ratings of facial attractiveness. Am J Orthod Dentofacial Orthop. Jan 2005;127(1):17-24.

23. Shell TL, Woods MG. Perception of facial esthetics: a comparison of similar class II cases treated with attempted growth modification or later orthognathic surgery. Angle Orthod. Aug 2003;73(4):365-373.

24. Raj M, Vig K, Beck FM, Larsen P, Shanker S. The perception of facial profile attractiveness by providers and consumers. [Master's]. Columbus: Section of Orthodontics, The Ohio State University; 2002.

25. Howells DJ, Shaw WC. The validity and reliability of ratings of dental and facial attractiveness for epidemiologic use. Am J Orthod. Nov 1985;88(5):402-408.

26. Aitken RC. Measurement of feelings using visual analogue scales. Proc $R$ Soc Med. Oct 1969;62(10):989-993. 
27. USA Statistics in Brief--Income. US Census Bureau [Web Page]. January 18, 2005. Available at: http://www.census.gov/statab/www/income.html. Accessed 4/26, 2005.

28. Tedesco LA, Albino JE, Cunat JJ, Slakter MJ, Waltz KJ. A dental-facial attractiveness scale. Part II. Consistency of perception. Am J Orthod. Jan 1983;83(1):4446.

29. Cochrane SM, Cunningham SJ, Hunt NP. A comparison of the perception of facial profile by the general public and 3 groups of clinicians. Int J Adult Orthodon Orthognath Surg. 1999;14(4):291-295.

30. Kerr WJ, O'Donnell JM. Panel perception of facial attractiveness. Br J Orthod. Nov 1990;17(4):299-304.

31. Yoon M, Jin TH, Dong JK. A study on the smile in Korean youth. J Korean Acad Prosthodont. 1992;30:259-270. 


\title{
CHAPTER 4
}

\section{MANUSCRIPT:}

\section{The Acceptability of Variations in Smile Arc and Buccal Corridor Space as Judged by Orthodontists and Laymen}

\begin{abstract}
Most studies of dental and facial esthetics have been based on attractiveness, but few studies have attempted to determine where the boundaries of acceptability lie. This web based study evaluated changes in acceptability based on computerized variations of smile arcs and buccal corridors of male and female smiles as judged by orthodontists and laypersons. The results of this study show that while the acceptability data follows trends in attractiveness, there exists a broad range of acceptability that is not evident in the attractiveness data. While orthodontists and laypersons both found smiles with excessive buccal corridors to be less acceptable than those with ideal or absent buccal corridors, they were still acceptable over $70 \%$ of the time. Flat smile arcs were only acceptable 50 $60 \%$ of the time, while smiles with ideal and excessive smile arcs were acceptable 84 $95 \%$ of the time. When studying dental and facial esthetics, the clinician must realize that although attractiveness scores may indicate a detrimental result, that result may still be acceptable to a majority of people.
\end{abstract}




\section{INTRODUCTION}

Facial and dental esthetics have become increasingly important during the last

decade. Recently, the field of orthodontics has experienced a "paradigm shift" to focus more on esthetics, with specific emphasis on soft tissues around the mouth. ${ }^{1}$

Although many current theories and clinical practices have evolved from anecdotal evidence or from restorative dentistry concepts, new data is emerging related to the science of esthetics. Two aspects of the esthetics have recently received great attention: smile arc and buccal corridor space.

Sarver ${ }^{2}$ recently focused his treatment and research on obtaining the ideal smile arc. Some orthodontists currently advocate maxillary expansion in the absence of crossbites in an attempt to reduce buccal corridor space. ${ }^{3}$ Frush and Fisher ${ }^{4}$ were some of the first to publish the concept of smile arc. Hulsey ${ }^{5}$ was one of the first to quantify the smile arc as a ratio to the lower lip. He found the smile arc to be an important contributing factor to an attractive smile and suggested that orthodontics affected the smile arc by adversely flattening it, thus determined how attractive a smile was judged.

Another concept originally attributed to Frush and Fisher ${ }^{4}$ was the presence of buccal corridor spaces. By definition, buccal corridor spaces were the negative space created between the buccal surfaces of the posterior teeth and the inner wall of the cheek. Too much buccal corridor resulted in large empty spaces, while too little looked artificial and was considered the essence of bad prosthetic denture esthetics. Hulsey ${ }^{5}$ found that buccal corridor spaces did not contribute significantly to smile esthetics. 
With the evolution of digital imaging, however, manipulation of the variables could be accomplished in a reliable and quantifiable manner. Sarver and Ackerman ${ }^{1}$ used computer simulation in their pilot studies. Kokich et $\mathrm{al}^{6}$ used variations of smile esthetics with a computer-based approach and found that orthodontists, general dentists, and lay people had varying levels at which they detected dental discrepancies.

Computer simulations of buccal corridor spaces have been studied and validate Hulsey's original findings. Roden-Johnson ${ }^{7}$ modified cropped smiles of three different archforms to display absent and large buccal corridor spaces, which were then rated on a visual analog scale. He concluded that orthodontists, general dentists, and laypeople each evaluate smiles differently. Orthodontists preferred normal to broad arch forms over untreated arch forms, while lay people demonstrated no preference between treated and untreated arch forms. More significantly, it was concluded that buccal corridor spaces did not have an effect on the smile ratings of orthodontists, general dentists, and lay people.

Moore et $a 1^{8}$ recently found that laypersons could differentiate between different percentages of buccal corridor. When laypersons were shown full face color photographs with five alterations in buccal corridor, they preferred faces with minimal buccal corridor spaces. The laypersons were able to distinguish changes in buccal corridor on all levels except when they became minimal. Laypersons preferred broad smiles significantly more than narrow smiles.

Data from Parekh et $\mathrm{al}^{9}$ who attempted to evaluate the clinical impact of smile esthetics using digital images and attractiveness scores rated on a VAS, found all smile arcs with absent and ideal buccal corridors were nearly identical for males and females, while excessive buccal corridors brought all ratings down. For both genders flat smile 
arcs overwhelmed the attractiveness of all buccal corridors and were rated in the lower $40 \%$ of the scale. The buccal corridors, especially for females in this study were relative small. Orthodontists, especially female orthodontists, used a greater range of rating instrument than laypersons. Buccal corridors and smile arcs generally made less difference to laypersons than to orthodontists. All raters, regardless of buccal corridors, generally preferred ideal smile arcs over excessive smile arcs and excessive smile arcs over flat smile arcs.

Understanding attractiveness of the smile arc and buccal corridor space is important, but another way to look at this problem is to ask where the boundaries of acceptability reside. This may be a more forgiving approach that allows for more latitude. One might rate attractiveness lower on a scale, but still find the appearance acceptable. Consequently, the purpose of this study was to determine what orthodontists and laypersons found esthetically acceptable for male and female models.

\section{MATERIALS AND METHODS}

\section{Image Manipulation}

After IRB approval, a digital archive was examined to obtain one frontal intraoral photograph of ideally aligned teeth, and one extraoral photograph that displayed esthetic lips from different patients. These images were modified using Adobe Photoshop ${ }^{\circledR} 7.0$ (San Jose, California) to create a bilaterally symmetric set of teeth and a set of lips without evidence of teeth and periodontium. The set of teeth were morphed using a 3-D spherical render function to modify the curvature of the incisal edges to fit twelve curves ranging from flat to accentuated based on sequentially increasing parabolic arcs, 
numbered 1-12 respectively. The lips were modified such that the lower lip would coincide with the number 7 curve.

The number 7 smile arc and lips were combined to form the ideal composite smile with all teeth displayed to the maxillary second molar. A black diffusing airbrush was used to create seven different sizes of buccal corridor quantified in relation to the teeth, numbered 1-6.

In order to create a "male" set of lips, a black gradient pattern overlay was used to create typical facial hair. A composite smile could then be completed by combining a set of teeth and lips with buccal corridor and facial hair as needed.

\section{Pilot Survey}

Pilot surveys were administered to experienced orthodontists (at least five years post residency) in order to set the standards for the ideal smile arc, the maximum acceptable accentuated smile arc, the ideal buccal corridor (i.e., the ideal amount of black space) and an excessive buccal corridor (i.e., too much black space). Quask ${ }^{\mathrm{TM}}$ Form Artist (New Canaan, Connecticut) was used to author the web survey and allowed the creation of emoticons, which are interactive sliding bars that display a changing picture when the slider is activated. One emoticon displayed smile arcs, another buccal corridors.

Orthodontists listed in the American Association of Orthodontists (AAO) Directory were contacted to participate in the pilot survey. The survey asked the rater for the year of completion of residency and an email address so that a follow up reliability survey could be completed at least two weeks later. The orthodontists were given written definitions of smile arcs and buccal corridors and asked to use the slider to set the visual 
standards for smile arc and buccal corridor variations for male and female smiles. Figure 3.1 illustrates an example question, available choices, and responses from the pilot survey.

\section{Main Survey}

Median values from the pilot survey were used to create images for the main study. Flat smile arcs and absent buccal corridors were considered to be inherently defined. The number 11 smile arc established the excessive smile arc because this was beyond the maximum acceptable level initially set by the orthodontists. Combinations of the three smile arc variations (flat, ideal, excessive) and the buccal corridor variations (none, ideal, excessive) were used to create 9 female and 9 male images. Figure 3.2 illustrates the 9 composite female smiles.

The main survey was created using Quask ${ }^{\mathrm{TM}}$ Form Artist. Different orthodontists were invited to participate. Available laypersons were contacted with conscious effort not to include those with dental affiliations.

Raters voluntarily provided demographic information including gender, U.S. geographical region, ethnic background, highest level of education completed, and any dental affiliation. Orthodontists were asked for the year they completed their professional training. If the rater was a layperson, they were asked to choose their income bracket from a drop down list.

The raters were asked to denote whether the displayed smile was acceptable or not. Raters were asked to evaluate the 9 female and 9 male smiles twice in order to 
determine reliability for a total of 36 smiles. The survey was designed such that the 36 smiles were randomized each time the survey was taken.

\section{Statistical Analysis}

Simple Kappa with $95 \%$ confidence interval statistics was used to the test the reliability of the main survey. Image acceptability was modeled using a logistic regression with rater group, buccal corridor, and smile arc as the independent variables. The Generalized Estimating Equation (GEE) was used to adjust for repeated-measures. Post hoc comparisons were done using contrasts which were adjusted using the stepdown Bonferroni method of Holm. The level of significance was set at a $p$ value of $<0.05$ for all analyses.

\section{RESULTS}

\section{Rater Demographics}

A total of 40 orthodontists participated in the first pilot survey. For the main survey responses, 115 were laypersons and 131 orthodontists. On average, orthodontists were 22 years post residency. The majority of laypeople were college educated, Caucasian and from the central US with a median income of $\$ 50,000$ to $\$ 75,000$.

\section{Reliability}

Simple Kappa statistics with $95 \%$ confidence intervals were used to evaluate the reliability for rating the acceptability of each image. Orthodontists showed good 
reliability ( $\kappa=0.79, \mathrm{LCB}=0.76, \mathrm{UCB}=0.83)$ and laypersons showed fair reliability ( $\kappa$ $=0.70, \mathrm{LCB}=0.66, \mathrm{UCB}=0.73$.

\section{Acceptability}

Acceptability represents a range of attractiveness measures and encompasses what is acceptable to a certain percentage of the population. For the purposes of this study the acceptability threshold was set at $67 \%$, which is beyond a simple majority and appears to represent a clear majority.

The summary of the logistic regression analysis is presented in Table 4.2 Significant effects were found in the following interactions: Group by Corridor, Group by Smile, and Corridor by Smile. When considering the acceptability of buccal corridors and smile arcs, these data are quite clear that none of the buccal corridors are acceptable for flat smile arcs, while all buccal corridors are highly acceptable for ideal and excessive smile arcs. Differences between smile arcs were statistically significant in every instance except for ideal and excessive smile arcs with an excessive buccal corridor. For ideal and excessive smile arcs with an excessive buccal corridor the acceptability was nearly identical, with the ideal and absent buccal corridor values being statistically significantly higher.

Orthodontist and laypersons found absent buccal corridors and ideal buccal corridors statistically more acceptable than excessive buccal corridors, but excessive buccal corridors were acceptable to over $70 \%$ of the raters.

Orthodontists and the laypersons found the ideal and excessive smile arcs statistically more acceptable than the flat smile arc. Laypersons also found the ideal 
smile arc statistically more acceptable than the excessive smile arc. All ratings for the ideal and excessive smile arcs were 84-95\%, while those for the flat smile arc ranged from 50 to $60 \%$.

Figures 4.3 and 4.4 summarize the interactions of laypersons and orthodontists rating the acceptability of buccal corridors variations and smile arc variations. Figure 4.5 summarizes the interactions of all raters when judging the acceptability of the combinations of smile arc and buccal corridor variations.

\section{DISCUSSION}

\section{Acceptability}

Excessive buccal corridors emerged as significantly less acceptable, but remained for all purposes in the highly acceptable range. This is simply a preference and not an exclusionary finding at this point. On the contrary, flat smile arcs were significantly and decidedly less acceptable than other smile arcs for all raters. Although minor distinctions existed between ideal and excessive smile arcs, these are highly acceptable for all raters. The attractiveness data from Parekh et $\mathrm{al}^{9}$ parallels the acceptability data for flat smile arcs.

Synergisms are present when looking at the combined effects of variations of smile arcs and buccal corridors. While excessive buccal corridors reduce the acceptability of all smile arcs, the most dramatic impact is flattening the smile arc on any buccal corridor. That single change will move the results, regardless of the buccal corridor space, to the unacceptable range. 
When observing the responses between the pilot and main surveys, it is particularly interesting to focus on the orthodontists. In the pilot surveys, orthodontists were asked to determine thresholds at which smile arcs and buccal corridors became excessive. One would expect smile characteristics falling within the non-ideal or excessive range as determined by the pilot studies to be unacceptable to orthodontists in the main study. This was not the case. In fact, excessive buccal corridors were acceptable over $71 \%$ of the time and excessive smile arcs were acceptable over $91 \%$ of the time. This variation may be due to the nature of the survey instrument; the pilot study used a dynamic image that allowed for direct comparisons, whereas the main study used randomly displayed static images that did not allow for direct comparison. Variation in responses may also be attributed to the relatively smaller sample size in the pilot surveys as well as the distribution of responses in the pilot study. In addition, the pilot surveys were one-dimensional and did not account for synergistic effects between smile arc and buccal corridors.

Clearly, using this method dramatic ranges of attractiveness ratings, ${ }^{6,10-12}$ and those of Parekh et al are not mirrored in acceptability preferences.

\section{CONCLUSIONS}

1. While excessive buccal corridors are rated as less acceptable than ideal and absent buccal corridors, they are still acceptable over $70 \%$ of the time.

2. Flat smile arcs, regardless of buccal corridor, display are only acceptable $50-60 \%$ of the time. 
3. Ideal smile and excessive smile arcs, regardless of buccal corridor display, are acceptable $84-95 \%$ of the time. 


\section{LEGEND}

Table 4.1 shows the significant interactions as determined by the linear regression. The level of significance is set at $\mathrm{p}<0.05$.

Table 4.2 shows individual signficant differences within the significant interactions determined by the linear regression. The level of significance is set at $\mathrm{p}<0.05$.

Figure 4.1 illustrates an example of an emoticon, displayed images, and results from the pilot survey.

Figure 4.2 represents the interactions between rater group and buccal corridor.

Significant differences are shown in Table. 4.2.

Figure 4.3 represents the interactions between rater group and smile arc. Significant differences are shown in in Table. 4.2.

Figure 4.4 represents the interactions between buccal corridor and smile arc. Significant differences are shown in Table. 4.2. 


\section{TABLES}

Logistic Regression with GEE for Repeated Measures

\begin{tabular}{lccc|} 
Source & DF & Chi-Square & Pr $>$ ChiSq \\
GROUP & 1 & 4.22 & 0.0398 \\
CORD & 2 & 63.07 & $<.0001$ \\
\hline GROUP*CORD & 2 & 8.68 & 0.0131 \\
\hline SMILE & 2 & 93.03 & $<.0001$ \\
\hline GROUP*SMILE & 2 & 13.21 & 0.0014 \\
CORD*SMILE & 4 & 57.11 & $<.0001$ \\
\hline GROUP*CORD*SMILE $^{*}{ }^{*}$ & 4 & 6.96 & 0.1379 \\
\hline
\end{tabular}

Table 4.1: Logistic Regression with GEE for Repeated Measures 
Buccal Corridor by Group

No BC / Laypersons

Ideal BC / Laypersons

Excessive BC / Laypersons

No $B C /$ Laypersons

No BC / Laypersons

Ideal BC / Laypersons

No $B C$ / Orthodontists

No $\mathrm{BC} /$ Orthodontists

Ideal BC / Orthodontists

Smile Arc by Group

Flat SA / Laypersons

Ideal SA / Laypersons

Excessive SA / Laypersons

\begin{tabular}{|l|}
\hline Flat SA / Laypersons \\
Flat SA / Laypersons \\
\hline Ideal SA / Laypersons \\
\hline Flat SA / Orthodontists \\
Flat SA / Orthodontists \\
\hline Ideal SA / Orthodontists \\
Smile Arc by Buccal Corridor \\
Flat SA
\end{tabular}

Flat SA

\begin{tabular}{|lll|}
\hline Excessive BC & Ideal BC & 0.0032 \\
Excessive BC & No BC & 0.0032 \\
\hline Ideal BC & No BC & 1.0000 \\
\hline Idea/ SA & & \\
\hline Excessive BC & Ideal BC & 0.0032 \\
Excessive BC & No BC & 0.0032 \\
\hline Ideal BC & No BC & 1.0000 \\
Excessive SA & & \\
\hline Excessive BC & Ideal BC & 0.0032 \\
Excessive BC & No BC & 0.0032 \\
\hline Ideal BC & No BC & 1.0000 \\
Buccal Corridor by Smile Arc & & \\
Excessive BC & & \\
\hline Flat SA & Excessive SA & 0.0032 \\
Flat SA & Ideal SA & 0.0032 \\
\hline Ideal SA & Excessive SA & 1.0000 \\
Ideal BC & & \\
\hline Flat SA & Excessive SA & 0.0032 \\
Flat SA & Ideal SA & 0.0032 \\
Ideal SA & Excessive SA & 0.0032 \\
\hline No BC & & \\
\hline Flat SA & Excessive SA & 0.0032 \\
Flat SA & Ideal SA & 0.0032 \\
Ideal SA & Excessive SA & 0.0032 \\
\hline
\end{tabular}

Table 4.2: Significant Interactions Based on Logistic Regression 


\section{FIGURES}

For the FEMALE smile below, what do you consider to be an IDEAL smile arc?

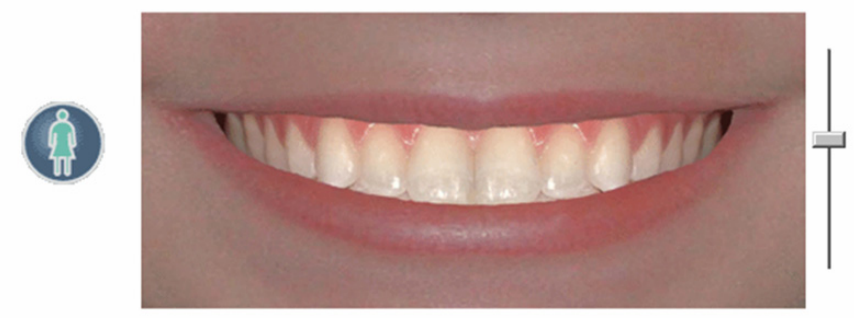

Use the slider on the right to adjust the curvature of the teeth.

First move the slider to the extreme to see the possible range of options, and then choose the appropriate position

Smile Arc Responses (Female and males were identical) Green $=$ Ideal, Red $=$ Accentuated
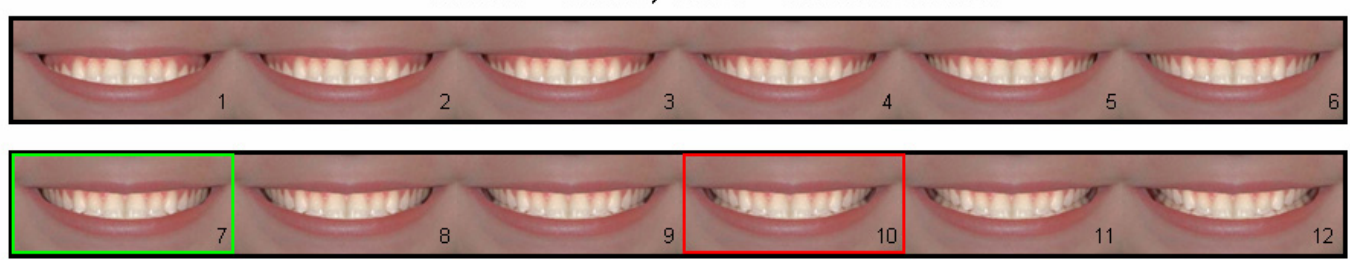

Buccal Corridor Responses (Female Model)

Green $=$ Ideal, Red $=$ Excessive

\begin{tabular}{|c|c|c|c|c|c|c|}
\hline 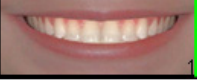 & $\begin{array}{l}\text { Tugnatevo } \\
2\end{array}$ & vosnatew & vounteve & evonires & Pountar & vounder \\
\hline
\end{tabular}

Buccal Corridor Responses (Male Model)

Green $=$ Ideal, Red $=$ Excessive

\begin{tabular}{|c|c|c|c|c|}
\hline 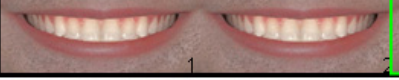 & Mounney? & vounartor & vouninger & 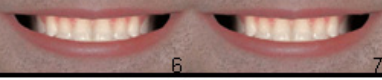 \\
\hline
\end{tabular}

Figure 4.1: Pilot Survey Example and Responses 


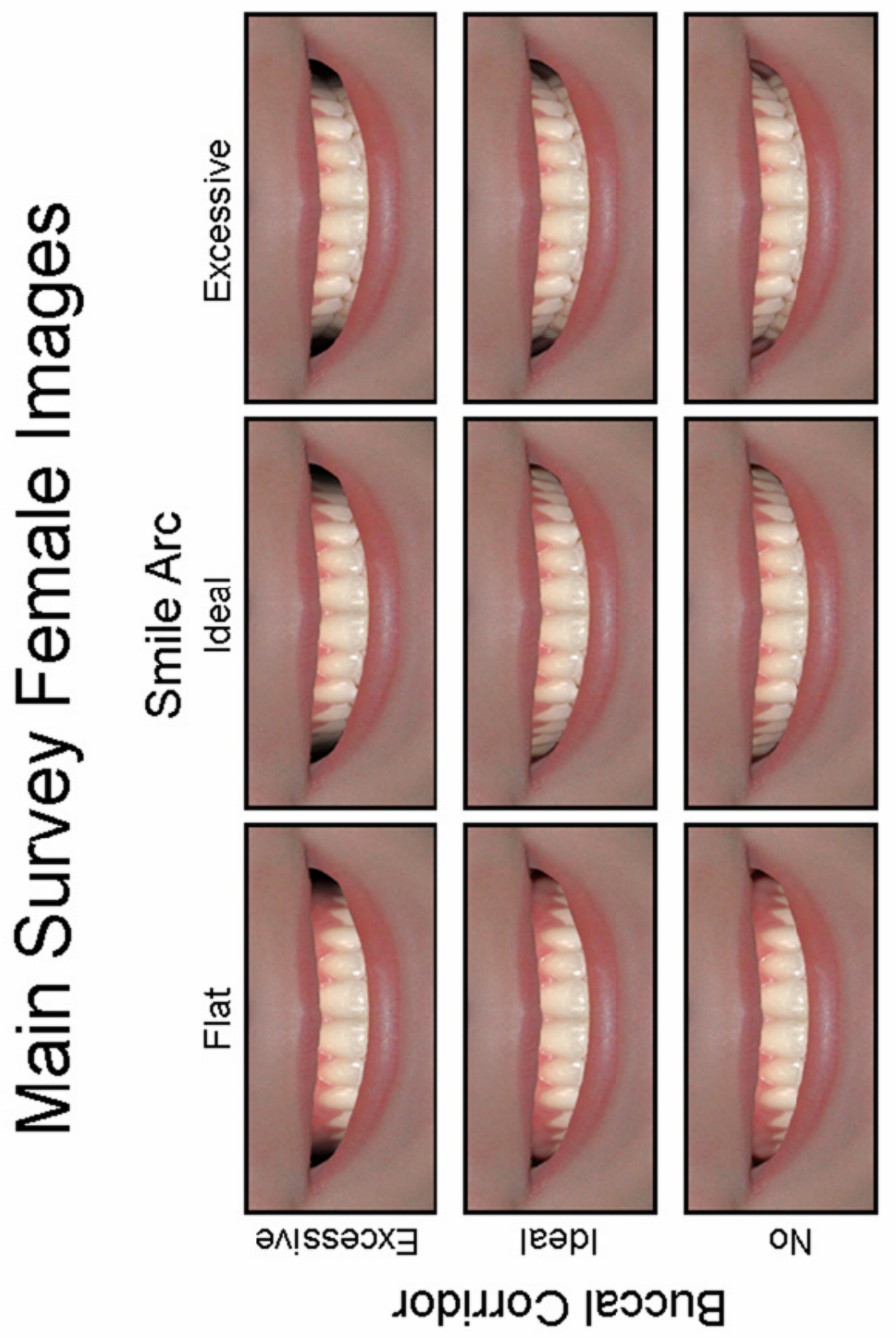

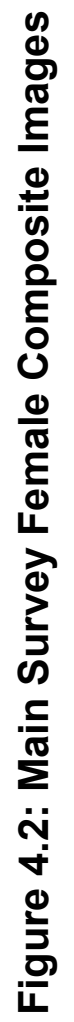




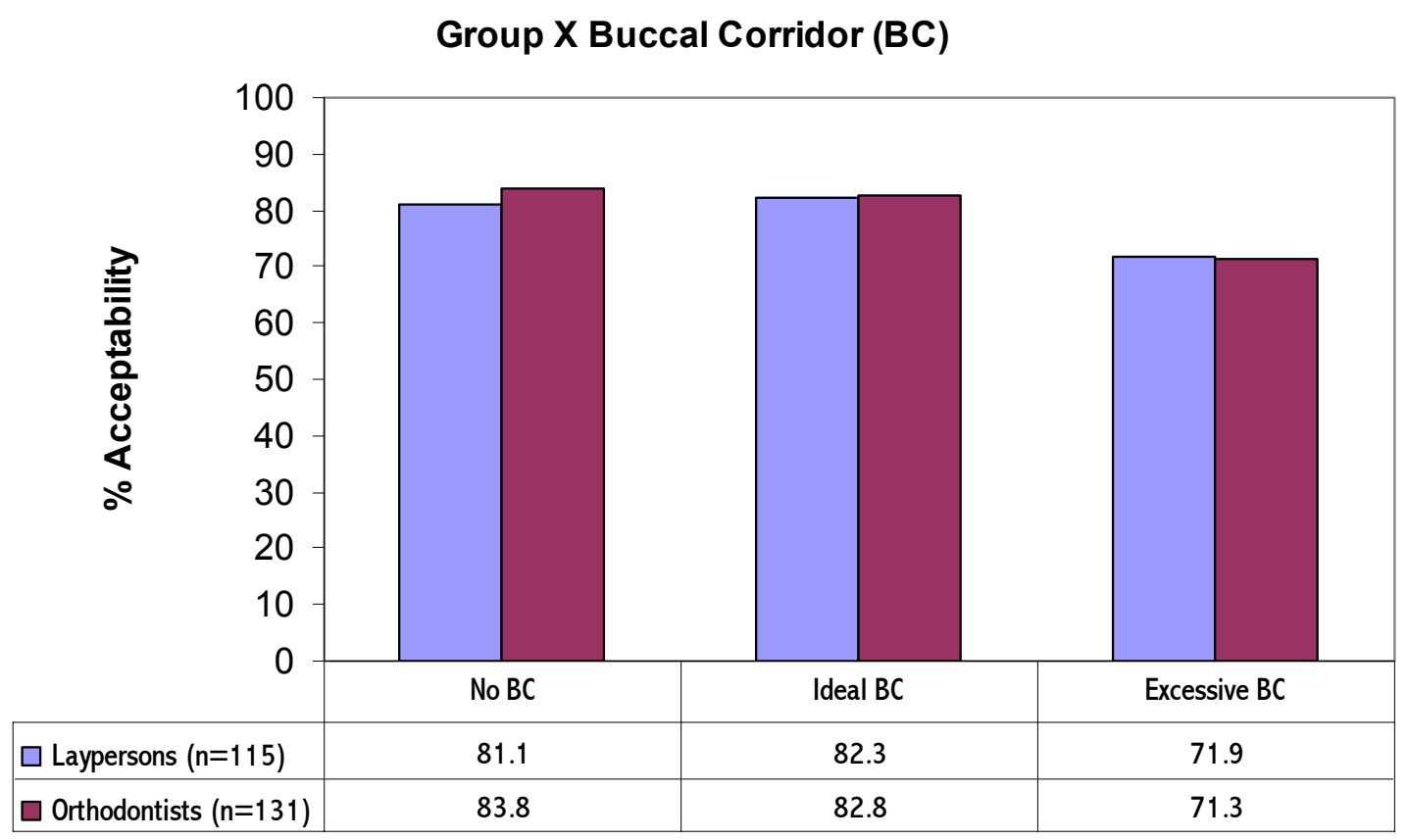

Figure 4.3: Group X Buccal Corridor (BC)

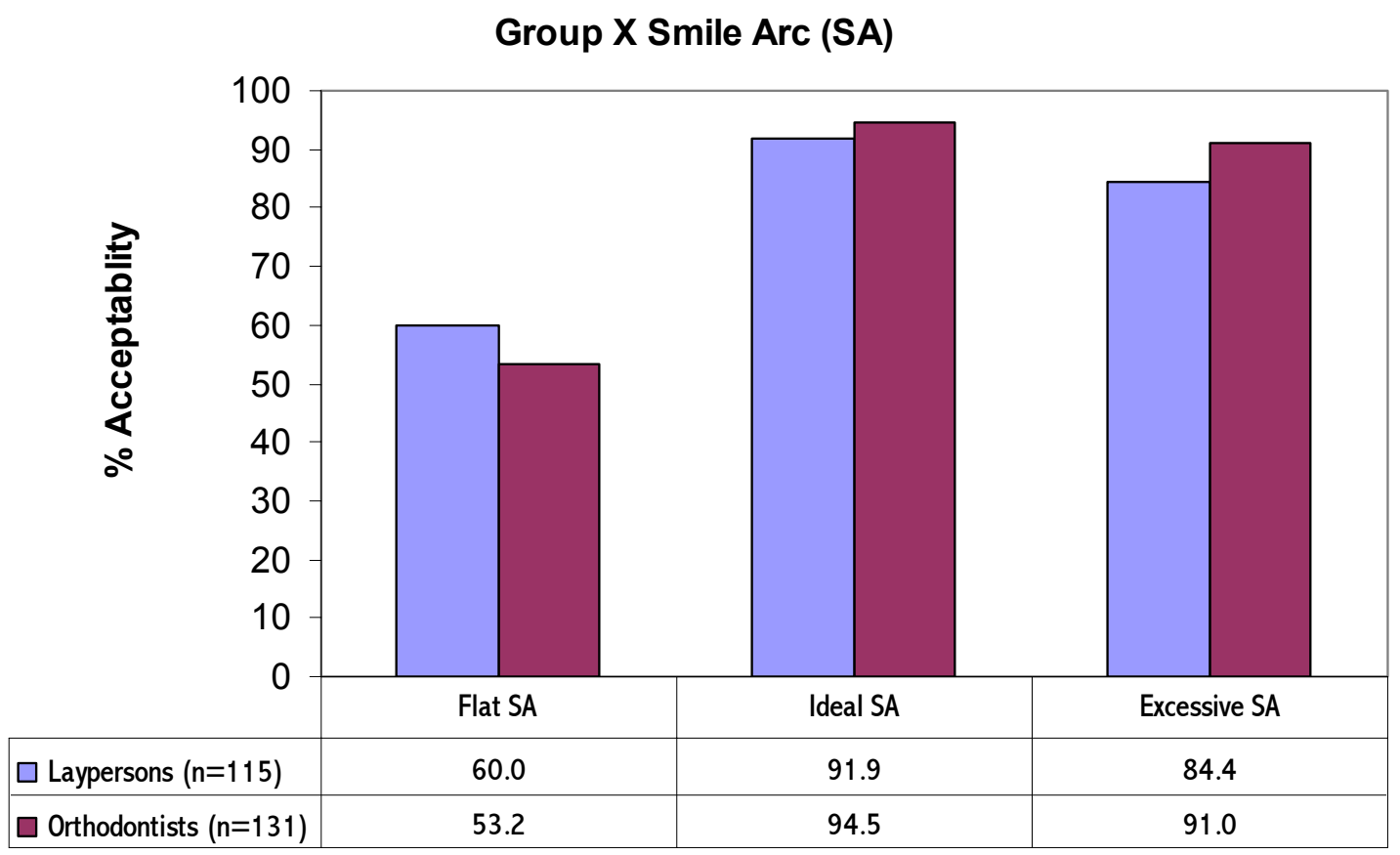

Figure 4.4: Group X Smile Arc (SA) 


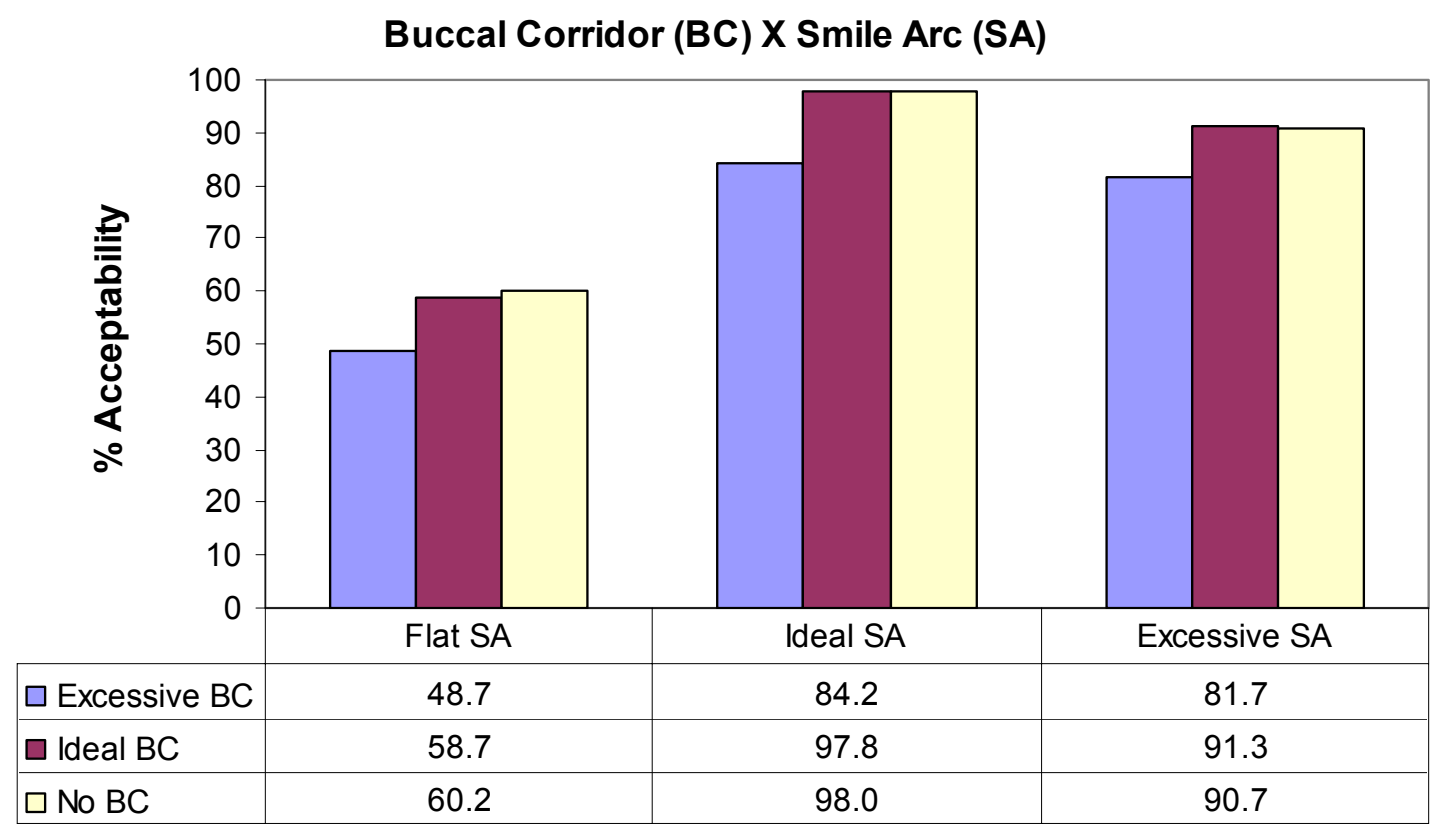

Figure 4.5: Buccal Corridor (BC) X Smile Arc (SA) 


\section{REFERENCES}

1. Ackerman JL, Proffit WR, Sarver DM. The emerging soft tissue paradigm in orthodontic diagnosis and treatment planning. Clin Orthod Res. May 1999;2(2):49-52.

2. Sarver DM. The importance of incisor positioning in the esthetic smile: the smile arc. Am J Orthod Dentofacial Orthop. Aug 2001;120(2):98-111.

3. McNamara JA. Maxillary transverse deficiency. Am J Orthod Dentofacial Orthop. May 2000;117(5):567-570.

4. Frush JP, Fisher RD. The Dynesthetic Interpretation of the Dentogenic Concept. $J$ Prosthet Dent. 1958;8:558.

5. Hulsey CM. An esthetic evaluation of lip-teeth relationships present in the smile. Am J Orthod. Feb 1970;57(2):132-144.

6. Kokich VO, Jr., Kiyak HA, Shapiro PA. Comparing the perception of dentists and lay people to altered dental esthetics. $J$ Esthet Dent. 1999;11(6):311-324.

7. Roden-Johnson D. The Effects of Buccal Corridor Spaces and Arch Form as Related to Smile Esthetics. Houston: Orthodontics, University of Texas Health Science Center at Houston, Dental Branch; 2003.

8. Moore T, Southard KA, Casko JS, Qian F, Southard TE. Buccal corridors and smile esthetics. Am J Orthod Dentofacial Orthop. Feb 2005;127(2):208-213.

9. Parekh JP, Fields HW, Rosenstiel SF, Beck FM. Perceptions of Selected Aspects of Smile Esthetics - Smile Arcs and Buccal Corridors. Columbus, OH: College of Dentistry, Section of Orthodontics, The Ohio State University; 2005.

10. Roden-Johnson D, Gallerno R, English J. The Effects of Buccal Corridor Spaces and Arch Form as Related to Smile Esthetics. Houston: Orthodontics, University of Texas Health Science Center at Houston, Dental Branch; 2003.

11. Raj M, Vig K, Beck FM, Larsen P, Shanker S. The perception of facial profile attractiveness by providers and consumers. [Master's]. Columbus: Section of Orthodontics, The Ohio State University; 2002.

12. Maple J, Vig K, Beck FM, Larsen P, Shanker S. A comparison of providers and consumers' perception of facial profile attractiveness [Master's]. Columbus: Section of Orthodontics, The Ohio State University; 2003. 


\section{CHAPTER 5}

\section{GENERAL CONCLUSIONS}

\section{Clinical Implications}

Based on the results of the current study and its agreement with other similar studies, there are some clinical implications to be considered. Care should be taken to not produce a flat smile arc in relation to the lower lip. Although there are limitations to orthodontic movements and anatomical considerations such as lip morphology, occlusal plane tip, and overbite, orthodontic techniques can aid in achievement of this goal. A full scope of options in treatment planning including orthognathic surgery, extraction, and incorporation of recent advances in orthodontic anchorage such as mini-screws and implants may also be a viable option for alteration of the smile arc. In regard to buccal corridor, expansion with or without the presence of a posterior crossbite may be justified in selected cases if the buccal corridor is determined to be excessive. It should be noted that such deviations from traditional orthodontic treatment should be entertained based on the esthetic demands of the patient, but may not be necessary or advisable for successful treatment of every case when weighed against functional and stability considerations. 


\section{Conclusions}

1. Emoticons and the VAS are a highly reliable method for evaluating the perception of smile esthetics when viewing cropped images of lips and teeth.

2. Orthodontists and laypersons can recognize alterations in smile arcs and buccal corridors, with orthodontists generally being more critical.

3. Orthodontists and laypersons prefer smiles in which the smile arc parallels the lower lip and buccal corridors are not excessive.

\section{Future Studies}

Future research is vital to understanding the current impact of subtle anatomic alterations on the impact of dental attractiveness. Areas to be investigated which currently have minimal data available and were beyond the scope of this study include:

1. Determining the exact point that smile arcs become too flat and buccal corridors too large.

2. Comparing morphologic differences in lips with alterations in smile components such as smile arc, buccal corridor, tooth shape, and color.

3. Assessing the impact of vertical changes in the dentition within the lips.

4. Assessing the perception of smile esthetics based on alterations of smile components in light of the entire face.

5. Comparing differences in perception of smile esthetics based on a rater's ethnic background, socioeconomic status, geographic location, education, and age.

6. Using 3-dimentional analysis and quantification to assess smile esthetics. 


\section{LIST OF REFERENCES}

USA Statistics in Brief--Income, US Census Bureau. 2005.

Ackerman, J. L., W. R. Proffit, et al. (1999). "The emerging soft tissue paradigm in orthodontic diagnosis and treatment planning." Clin Orthod Res 2(2): 49-52.

Aitken, R. C. (1969). "Measurement of feelings using visual analogue scales." Proc R Soc Med 62(10): 989-93.

Angle, E. (1907). Malocclusion of the Teeth. Philadelphia, SS White Dental Mfg Co.

Baker, B. W. and M. G. Woods (2001). "The role of the divine proportion in the esthetic improvement of patients undergoing combined orthodontic/orthognathic surgical treatment." Int J Adult Orthodon Orthognath Surg 16(2): 108-20.

Baldwin, D. C. (1980). "Appearance and aesthetics in oral health." Community Dent Oral Epidemiol 8(5): 244-56.

Beyer, J. W. and S. J. Lindauer (1998). "Evaluation of dental midline position." Semin Orthod 4(3): 146-52.

Brislin, R. and S. Lewis (1968). "Dating and Physical Attractiveness: Replication." Psychological Reports 22(3, Pt. 1): 976.

Burden, D. J. (1995). "The ranking of dental aesthetics." Br J Orthod 22(3): 259-61.

Byrne, D., O. London, et al. (1968). "The effects of physical attractiveness, sex, and attitude similarity on interpersonal attraction." Journal of Personality 36(2): 259271.

Caputy, G. G. and R. S. Flowers (1993). "Computer imaging: true or false." Hawaii Med J 52(12): 349-51. 
Carnegie, D. (1936). How to win friends and influence people. New York,, Simon and Schuster.

Chalifoux, P. R. (1996). "Perception esthetics: factors that affect smile design." J Esthet Dent 8(4): 189-92.

Cipra, D. L. and J. G. Wall (1991). "Esthetics in fixed and removable prosthodontics: the composition of a smile." J Tenn Dent Assoc 71(4): 24-9.

Cleffore, M. and E. Salster (1973). "The effect of physical attractiveness on teacher expectations." Soc Educ(46): 248-258.

Cochrane, S. M., S. J. Cunningham, et al. (1999). "A comparison of the perception of facial profile by the general public and 3 groups of clinicians." Int J Adult Orthodon Orthognath Surg 14(4): 291-5.

Cunningham, M. R., A. P. Barbee, et al. (1990). "What do women want? Facialmetric assessment of multiple motives in the perception of male facial physical attractiveness." J Pers Soc Psychol 59(1): 61-72.

Dion, K., E. Berscheid, et al. (1972). "What is beautiful is good." Journal of Personality \& Social Psychology Vol. 24(3): 285-290.

Dong, J. K., T. H. Jin, et al. (1999). "The esthetics of the smile: a review of some recent studies." Int J Prosthodont 12(1): 9-19.

Eaton, J., D. McTigue, et al. (2005). "Attitudes of Contemporary Parents Toward Behavior Management Techniques Used in Pediatric Dentistry." J of Pediatric Dentistry(Accepted 4/2005).

Evans, R. and W. Shaw (1987). "Preliminary evaluation of an illustrated scale for rating dental attractiveness." Eur J Orthod 9(4): 314-8.

Farrow, A. L., K. Zarrinnia, et al. (1993). "Bimaxillary protrusion in black Americans--an esthetic evaluation and the treatment considerations." Am J Orthod Dentofacial Orthop 104(3): 240-50.

Feeley, R. T. (1995). "Cosmetics and the esthetic patient and laboratory communication." Oral Health 85(8): 9-12, 14.

Frush, J. P. and R. D. Fisher (1955). "Introduction to dentogenic restorations." J Prosthet Dent 5: 586-595. 
Frush, J. P. and R. D. Fisher (1958). "The Dynesthetic Interpretation of the Dentogenic Concept." J Prosthet Dent 8: 558.

Gianelly, A. A. (2003). "Arch width after extraction and nonextraction treatment." Am J Orthod Dentofacial Orthop 123(1): 25-8.

Graber, L. W. and G. W. Lucker (1980). "Dental esthetic self-evaluation and satisfaction." Am J Orthod 77(2): 163-73.

Howells, D. J. and W. C. Shaw (1985). "The validity and reliability of ratings of dental and facial attractiveness for epidemiologic use." Am J Orthod 88(5): 402-8.

Hsia, H. C. and J. G. Thomson (2003). "Differences in breast shape preferences between plastic surgeons and patients seeking breast augmentation." Plast Reconstr Surg 112(1): 312-20; discussion 321-2.

Hulsey, C. M. (1970). "An esthetic evaluation of lip-teeth relationships present in the smile." Am J Orthod 57(2): 132-44.

Hunt, O., P. Hepper, et al. (2001). "Professional perceptions of the benefits of orthodontic treatment." Eur J Orthod 23(3): 315-23.

Huston, T. L. (1973). "Ambiguity of acceptance, social desirability, and dating choice." Journal of Experimental Social Psychology Vol. 9(1): 32-42.

Jabourian, P. (1997). "[Plastic surgery, aging and the smile]." Orthod Fr 68(1): 13-4.

Jenny, J. and N. C. Cons (1996). "Comparing and contrasting two orthodontic indices, the Index of Orthodontic Treatment need and the Dental Aesthetic Index." Am J Orthod Dentofacial Orthop 110(4): 410-6.

Jenny, J., N. C. Cons, et al. (1983). "Comparison of SASOC, a measure of dental aesthetics, with three orthodontic indices and orthodontist judgment." Community Dent Oral Epidemiol 11(4): 236-41.

Jenny, J., N. C. Cons, et al. (1980). "Test of a method to determine socially acceptable occlusal conditions." Community Dent Oral Epidemiol 8(8): 424-33.

Jenny, J. and J. M. Proshek (1986). "Visibility and prestige of occupations and the importance of dental appearance." J Can Dent Assoc 52(12): 987-9. 
Johnson, D. K. and R. J. Smith (1995). "Smile esthetics after orthodontic treatment with and without extraction of four first premolars." Am J Orthod Dentofacial Orthop 108(2): 162-7.

Johnston, C. D., D. J. Burden, et al. (1999). "The influence of dental to facial midline discrepancies on dental attractiveness ratings." Eur J Orthod 21(5): 517-22.

Kane, A. A., T. K. Pilgram, et al. (2000). "Long-term outcome of cleft lip nasal reconstruction in childhood." Plast Reconstr Surg 105(5): 1600-8.

Kelly, A. M. (1998). "Does the clinically significant difference in visual analog scale pain scores vary with gender, age, or cause of pain?" Acad Emerg Med 5(11): 108690 .

Kerr, W. J. and J. M. O'Donnell (1990). "Panel perception of facial attractiveness." $\underline{\mathrm{Br} J}$ Orthod 17(4): 299-304.

Kim, E. and A. A. Gianelly (2003). "Extraction vs nonextraction: arch widths and smile esthetics." Angle Orthod 73(4): 354-8.

Kleck, R. E. and C. Rubenstein (1975). "Physical attractiveness, perceived attitude similarity, and interpersonal attraction in an opposite-sex encounter." Journal of Personality \& Social Psychology 31(1): 107-114.

Kokich, V. O., Jr., H. A. Kiyak, et al. (1999). "Comparing the perception of dentists and lay people to altered dental esthetics." J Esthet Dent 11(6): 311-24.

Levinson, N. A. (1990). "Psychologic facets of esthetic dental health care: a developmental perspective." J Prosthet Dent 64(4): 486-91.

Levy, S. M., J. J. Warren, et al. (2002). "Follow-up study of dental students' esthetic perceptions of mild dental fluorosis." Community Dent Oral Epidemiol 30(1): 248.

Lombardi, R. E. (1973). "The principles of visual perception and their clinical application to denture esthetics." J Prosthet Dent 29(4): 358-82.

Mackley, R. J. (1993). "An evaluation of smiles before and after orthodontic treatment." Angle Orthod 63(3): 183-9; discussion 190. 
Maple, J., K. Vig, et al. (2003). A comparison of providers and consumers' perception of facial profile attractiveness. Section of Orthodontics. Columbus, The Ohio State University: 56.

Marks, M. H. and P. S. Rosen (1991). "Adult orthodontics: periodontic and cosmetic enhancements." Compendium 12(8): 584, 586, 588 passim.

McNamara, J. A. (2000). "Maxillary transverse deficiency." Am J Orthod Dentofacial Orthop 117(5): 567-70.

Michiels, G. and A. H. Sather (1994). "Determinants of facial attractiveness in a sample of white women." Int J Adult Orthodon Orthognath Surg 9(2): 95-103.

Miller, A. G. (1970). "Role of physical attractiveness in impression formation." Psychonomic Science 19(4): 241-243.

Moore, T., K. A. Southard, et al. (2005). "Buccal corridors and smile esthetics." Am J Orthod Dentofacial Orthop 127(2): 208-13.

Morley, J. and J. Eubank (2001). "Macroesthetic elements of smile design." J Am Dent Assoc 132(1): 39-45.

Moskowitz, M. E. and A. Nayyar (1995). "Determinants of dental esthetics: a rational for smile analysis and treatment." Compend Contin Educ Dent 16(12): 1164, 1166 , passim; quiz 1186.

Nakajima E, M. T., Yanagasawa M. (1985). "The Japanese sense of beauty and facial proportions. II. The beautiful face and the $2^{1 / 2}$ rule." Quintescence International(9): 629-637.

O'Neill, K., M. Harkness, et al. (2000). "Ratings of profile attractiveness after functional appliance treatment." Am J Orthod Dentofacial Orthop 118(4): 371-6; discussion 377.

Otta, E., B. B. Lira, et al. (1994). "The effect of smiling and of head tilting on person perception." J Psychol 128(3): 323-31.

Parekh, J. P., H. W. Fields, et al. (2005). Perceptions of Selected Aspects of Smile Esthetics - Smile Arcs and Buccal Corridors. College of Dentistry, Section of Orthodontics. Columbus, $\mathrm{OH}$, The Ohio State University. 
Peck, S., L. Peck, et al. (1992). "The gingival smile line." Angle Orthod 62(2): 91-100; discussion 101-2.

Perrin, F. A. C. (1921). "Physical Attractiveness and Repulsiveness." Journal of Experimental Psychology 4: 203-217.

Phillips, C., T. Griffin, et al. (1995). "Perception of facial attractiveness by patients, peers, and professionals." Int J Adult Orthodon Orthognath Surg 10(2): 127-35.

Phillips, C., C. J. Trentini, et al. (1992). "The effect of treatment on facial attractiveness." J Oral Maxillofac Surg 50(6): 590-4.

Phillips, C., C. Tulloch, et al. (1992). "Rating of facial attractiveness." Community Dent Oral Epidemiol 20(4): 214-20.

Powell, C. V., A. M. Kelly, et al. (2001). "Determining the minimum clinically significant difference in visual analog pain score for children." Ann Emerg Med 37(1): 28-31.

Preston, J. D. (1993). "The golden proportion revisited." J Esthet Dent 5(6): 247-51.

Proffit, W. R., H. W. Fields, et al. (2006). Contemporary orthodontics. St. Louis, Mosby.

Raj, M., K. Vig, et al. (2002). The perception of facial profile attractiveness by providers and consumers. Section of Orthodontics. Columbus, The Ohio State University: 71.

Ricketts, R. M. (1982). "The biologic significance of the divine proportion and Fibonacci series." Am J Orthod 81(5): 351-70.

Ricketts, R. M. (1982). "Divine proportion in facial esthetics." Clin Plast Surg 9(4): 40122 .

Roden-Johnson, D., R. Gallerno, et al. (2003). The Effects of Buccal Corridor Spaces and Arch Form as Related to Smile Esthetics. Orthodontics. Houston, University of Texas Health Science Center at Houston, Dental Branch.

Rosenstiel, S. F. and R. G. Rashid (2002). "Public preferences for anterior tooth variations: a web-based study." J Esthet Restor Dent 14(2): 97-106.

Rosenstiel, S. F., D. H. Ward, et al. (2000). "Dentists' preferences of anterior tooth proportion--a web-based study." J Prosthodont 9(3): 123-36. 
Sarver, D. M. (2001). "The importance of incisor positioning in the esthetic smile: the smile arc." Am J Orthod Dentofacial Orthop 120(2): 98-111.

Sarver, D. M. and J. L. Ackerman (2000). "Orthodontics about face: the re-emergence of the esthetic paradigm." Am J Orthod Dentofacial Orthop 117(5): 575-6.

Schlosser, J. B., C. B. Preston, et al. (2005). "The effects of computer-aided anteroposterior maxillary incisor movement on ratings of facial attractiveness." Am J Orthod Dentofacial Orthop 127(1): 17-24.

Shaw, W. C. (1981). "The influence of children's dentofacial appearance on their social attractiveness as judged by peers and lay adults." Am J Orthod 79(4): 399-415.

Shaw, W. C. and S. Humphreys (1982). "Influence of children's dentofacial appearance on teacher expectations." Community Dent Oral Epidemiol 10(6): 313-9.

Shaw, W. C., G. Rees, et al. (1985). "The influence of dentofacial appearance on the social attractiveness of young adults." Am J Orthod 87(1): 21-6.

Shell, T. L. and M. G. Woods (2003). "Perception of facial esthetics: a comparison of similar class II cases treated with attempted growth modification or later orthognathic surgery." Angle Orthod 73(4): 365-73.

Snow, S. R. (1999). "Esthetic smile analysis of maxillary anterior tooth width: the golden percentage." J Esthet Dent 11(4): 177-84.

Tedesco, L. A., J. E. Albino, et al. (1983). "A dental-facial attractiveness scale. Part II. Consistency of perception." Am J Orthod 83(1): 44-6.

Thomas, J. L., C. Hayes, et al. (2003). "The effect of axial midline angulation on dental esthetics." Angle Orthod 73(4): 359-64.

Tjan, A. H., G. D. Miller, et al. (1984). "Some esthetic factors in a smile." J Prosthet Dent 51(1): 24-8.

Tobiasen, J. M. (1989). "Scaling facial impairment." Cleft Palate J 26(3): 249-54; discussion 254.

Todd, K. H., K. G. Funk, et al. (1996). "Clinical significance of reported changes in pain severity." Ann Emerg Med 27(4): 485-9. 
Valo, T. S. (1995). "Anterior esthetics and the visual arts: beauty, elements of composition, and their clinical application to dentistry." Curr Opin Cosmet Dent: 24-32.

Walster, E., V. Aronson, et al. (1966). "Importance of physical attractiveness in dating behavior." Journal of Personality \& Social Psychology 4(5): 508-516.

Williams, J. L. (1914). "A new classification of human tooth forms with special reference to a new system of artificial teeth." Dent Cosmos 56: 627-8.

Yamamoto, L. G., J. T. Nomura, et al. (2003). "Minimum clinically significant VAS differences for simultaneous (paired) interval serial pain assessments." Am J Emerg Med 21(3): 176-9.

Yoon, M., T. Jin, et al. (1992). "A study on the smile in Korean youth." J Korean Acad Prosthodont 30: 259-270.

Zisapel, N. and T. Nir (2003). "Determination of the minimal clinically significant difference on a patient visual analog sleep quality scale." J Sleep Res 12(4): 2918 . 


\section{APPENDIX A}

ADDITIONAL TABLES AND FIGURES 


$\begin{array}{ccccc}\text { Model Gender } & \begin{array}{c}\text { Ideal } \\ \text { Smile Arc }\end{array} & \begin{array}{c}\text { Accentuated } \\ \text { Smile Arc }\end{array} & \begin{array}{c}\text { Ideal } \\ \text { Buccal Corridor }\end{array} & \begin{array}{c}\text { Excessive } \\ \text { Buccal Corridor }\end{array} \\ \text { Female } & 7 & 10 & 2 & 4 \\ \text { Male } & 7 & 10 & 3 & 5\end{array}$

\section{Table A.1: Pilot Survey Responses}




\author{
Gender / Affiliation \\ Male Orthodontist \\ Male Layperson \\ Female Layperson \\ Female Orthodntist
}

Education

Professional degree, DDS, MD, PhD, MS, etc.

College undergraduate degree

Some college

Associates degree

Some college or other education after high school

12th grade completed

Some high school

$\begin{array}{clc}\mathbf{n} & \text { Ethnicity } & \mathbf{n} \\ 116 & \text { Caucasian / White } & 215 \\ 80 & \text { Asian / Pacific Islander } & 18 \\ 55 & \text { Hispanic / Latin American } & 6 \\ 15 & \text { African American / Black } & 3 \\ & \text { American Indian / Alaskan } & \\ & \text { Native } & 2 \\ & & \\ \mathbf{n} & \text { Income } & \mathbf{n} \\ 159 & \text { Less than } \$ 10,000 & 5 \\ 45 & \$ 10,001-\$ 30,000 & 10 \\ 23 & \$ 30,001-\$ 50,000 & 19 \\ 10 & \$ 50,001-\$ 75,000 & 26 \\ 6 & \$ 75,001-\$ 100,000 & 23 \\ 2 & \$ 100,001-\$ 150,000 & 12 \\ 0 & \text { More than } \$ 150,000 & 5\end{array}$

$\begin{array}{lc}\text { US Region } & \mathbf{n} \\ \text { Central } & 102 \\ \text { West } & 30 \\ \text { South } & 19 \\ \text { North } & 18 \\ \text { Northeast } & 15 \\ \text { Southeast } & 15 \\ \text { East } & 11 \\ \text { Northwest } & 11 \\ \text { Southwest } & 7\end{array}$

Table A.2: Distribution of Responses 


\section{Pilot Survey}

(intraclass correlation coefficients and $95 \%$ confidence intervals)

Variable
Overall
Overall Smile
Overall Buccal Corridor
Ideal Smile Arc Female
Ideal Smile Arc Male
Acc Smile Arc Female
Acc Smile Arc Male
Ideal Buccal Corridor Female
Ideal Buccal Corridor Male
Acc Buccal Corridor Female
Acc Buccal Corridor Male

$\begin{array}{lll}\text { ICC } & \text { LCB } & \text { UCB } \\ 0.94 & 0.91 & 0.95 \\ 0.77 & 0.67 & 0.84 \\ 0.77 & 0.66 & 0.85 \\ 0.47 & 0.08 & 0.73 \\ 0.66 & 0.35 & 0.84 \\ 0.50 & 0.13 & 0.75 \\ 0.61 & 0.28 & 0.81 \\ 0.65 & 0.27 & 0.86 \\ 0.65 & 0.28 & 0.86 \\ 0.61 & 0.22 & 0.84 \\ 0.55 & 0.12 & 0.81\end{array}$

Main Survey - Attractiveness

(intraclass correlation coefficients and $95 \%$ confidence intervals)

$\begin{array}{lccc}\text { Variable } & \text { ICC } & \text { LCB } & \text { UCB } \\ \text { Overall } & 0.87 & 0.85 & 0.89 \\ \text { Lay } & 0.91 & 0.89 & 0.93 \\ \text { Ortho } & 0.81 & 0.77 & 0.85\end{array}$

Main Survey - Acceptability

(simple kappa and $95 \%$ confidence intervals)

$\begin{array}{lccc}\text { Variable } & \text { K } & \text { LCB } & \text { UCB } \\ \text { Overall } & 0.74 & 0.72 & 0.77 \\ \text { Lay } & 0.70 & 0.66 & 0.73 \\ \text { Ortho } & 0.79 & 0.76 & 0.83\end{array}$

Table A.3: Reliability 


\begin{tabular}{|c|c|c|c|c|}
\hline Effect & Num Df & Den Df & F Value & Pr>F \\
\hline GROUP & 1 & 242 & 0.02 & 0.889 \\
\hline CORD & 2 & 242 & 87.69 & $<.0001$ \\
\hline GROUP*CORD & 2 & 242 & 8.6 & 0.0002 \\
\hline SMILE & 2 & 242 & 282.46 & $<.0001$ \\
\hline GROUP*SMILE & 2 & 242 & 22.4 & $<.0001$ \\
\hline CORD*SMILE & 4 & 242 & 33.74 & $<.0001$ \\
\hline GROUP*CORD*SMILE & 4 & 242 & 10.97 & $<.0001$ \\
\hline RATERGEN & 1 & 242 & 0.11 & 0.746 \\
\hline RATERGENGROUP & 1 & 242 & 1.83 & 0.1773 \\
\hline RATERGENCORD & 2 & 242 & 0.35 & 0.7058 \\
\hline RATERGEN*GROUP*CORD & 2 & 242 & 0.25 & 0.7786 \\
\hline RATERGEN*SMILE & 2 & 242 & 3.88 & 0.0219 \\
\hline RATERGEN*GROUP*SMILE & 2 & 242 & 2.63 & 0.0744 \\
\hline RATERGEN*CORD*SMILE & 4 & 242 & 2.81 & 0.0263 \\
\hline RATE $^{*} \mathrm{GROU}^{*} \mathrm{CORD}^{*}$ SMILE & 4 & 242 & 3.08 & 0.017 \\
\hline MODELGEN & 1 & 242 & 140.73 & $<.0001$ \\
\hline GROUP*MODELGEN & 1 & 242 & 0.07 & 0.791 \\
\hline MODELGENCORD & 2 & 242 & 45.19 & $<.0001$ \\
\hline GROUP*MODELGEN*CORD & 2 & 242 & 1.99 & 0.1393 \\
\hline MODELGEN℠ILE & 2 & 242 & 39.14 & $<.0001$ \\
\hline GROUP*MODELGEN*SMILE & 2 & 242 & 2.77 & 0.0648 \\
\hline MODELGEN ${ }^{*} \mathrm{CORD}^{*}$ SMILE & 4 & 242 & 10.58 & $<.0001$ \\
\hline GROU*MODE*CORD*SMILE & 4 & 242 & 1.85 & 0.1201 \\
\hline RATERGEN*MODELGEN & 1 & 242 & 0.36 & 0.5517 \\
\hline RATERG*GROUP*MODELGE & 1 & 242 & 2.44 & 0.1198 \\
\hline RATERGE*MODELGE*CORD & 2 & 242 & 0.02 & 0.9763 \\
\hline RATE*GROU*MODEL*CORD & 2 & 242 & 0.15 & 0.8577 \\
\hline RATERG*MODELGE*SMILE & 2 & 242 & 2.56 & 0.0791 \\
\hline RATE*GROU*MODE*SMILE & 2 & 242 & 0.23 & 0.7928 \\
\hline RATE*MODE*CORD*SMILE & 4 & 242 & 1.69 & 0.1536 \\
\hline $\mathrm{RAT}^{*} \mathrm{GRO}{ }^{*} \mathrm{MOD}^{*} \mathrm{COR}^{*} \mathrm{SMIL}$ & 4 & 242 & 0.21 & 0.9314 \\
\hline
\end{tabular}

Table A.4: ANOVA Summary for Attractiveness 


\begin{tabular}{ccccc}
\multicolumn{2}{c}{ Moore et al Study } & \multicolumn{3}{c}{ Current Study } \\
BC Classification & BC $\%$ & BC No & Pilot Results & BC\% \\
Broad & $2 \%$ & 1 & None & $3 \%$ \\
& & $2(B G 7)$ & Ideal Female & $6 \%$ \\
Medium-Broad & $10 \%$ & $3(\mathrm{M} 7)$ & Ideal Male & $11 \%$ \\
Medium & $15 \%$ & $4(\mathrm{BG} 6)$ & Excessive Female & $14 \%$ \\
Medium-narrow & $22 \%$ & $5(\mathrm{M} 6)$ & Excessive Male & $19 \%$ \\
Narrow & $28 \%$ & $6(\mathrm{M} 5)$ & & $27 \%$ \\
& & $7(\mathrm{M} 4)$ & & $32 \%$
\end{tabular}

Table A.5: Buccal Corridor Percentages 


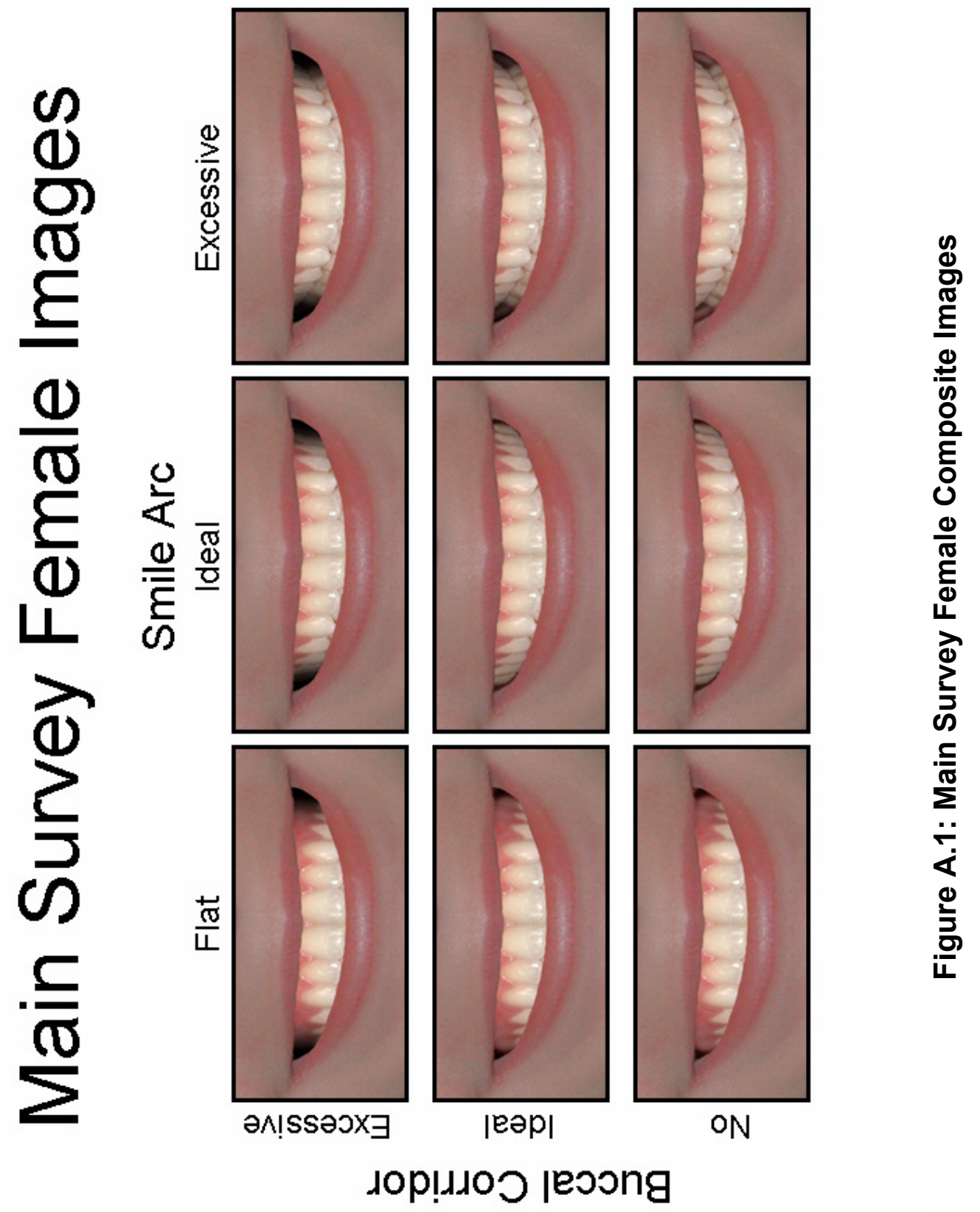




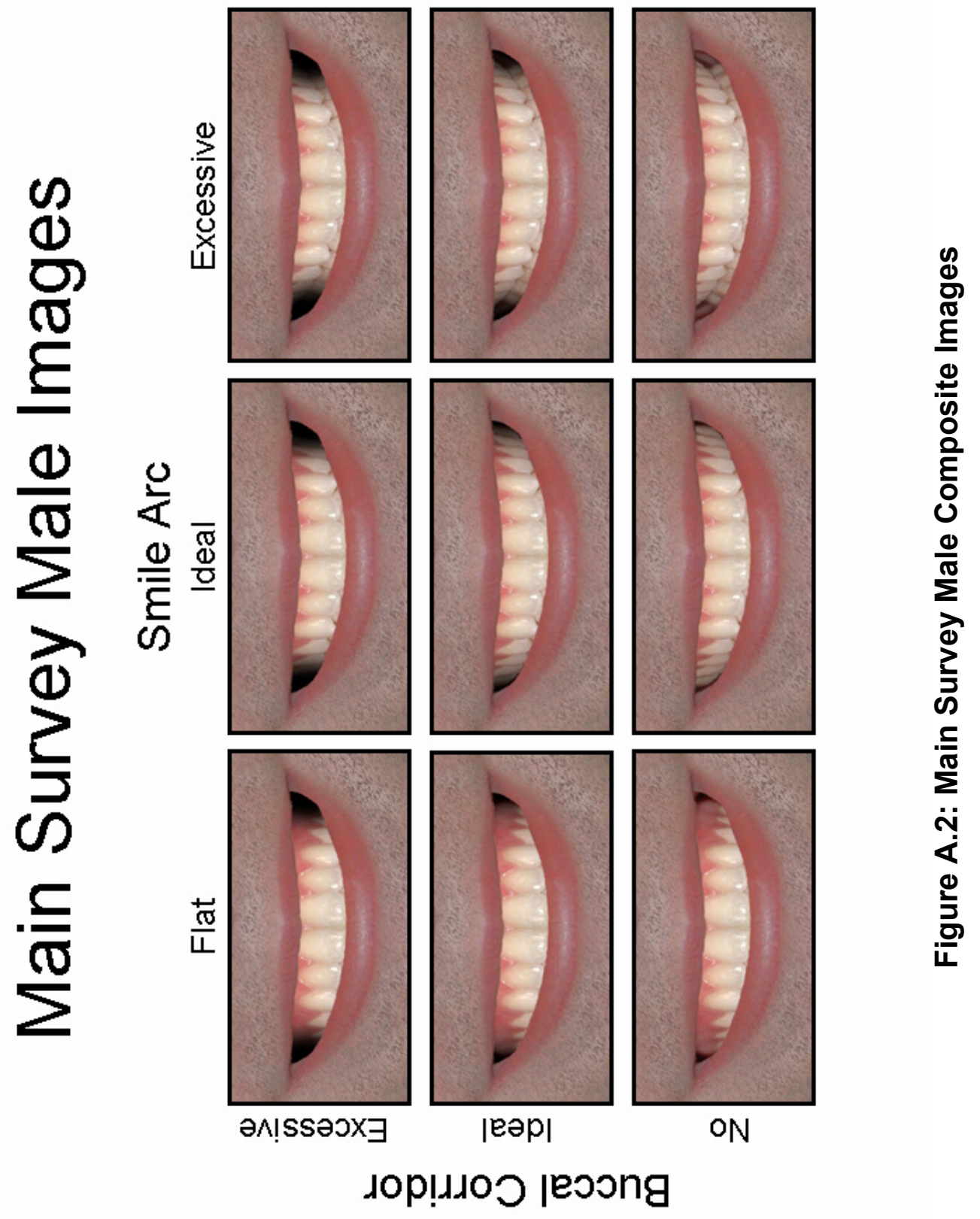




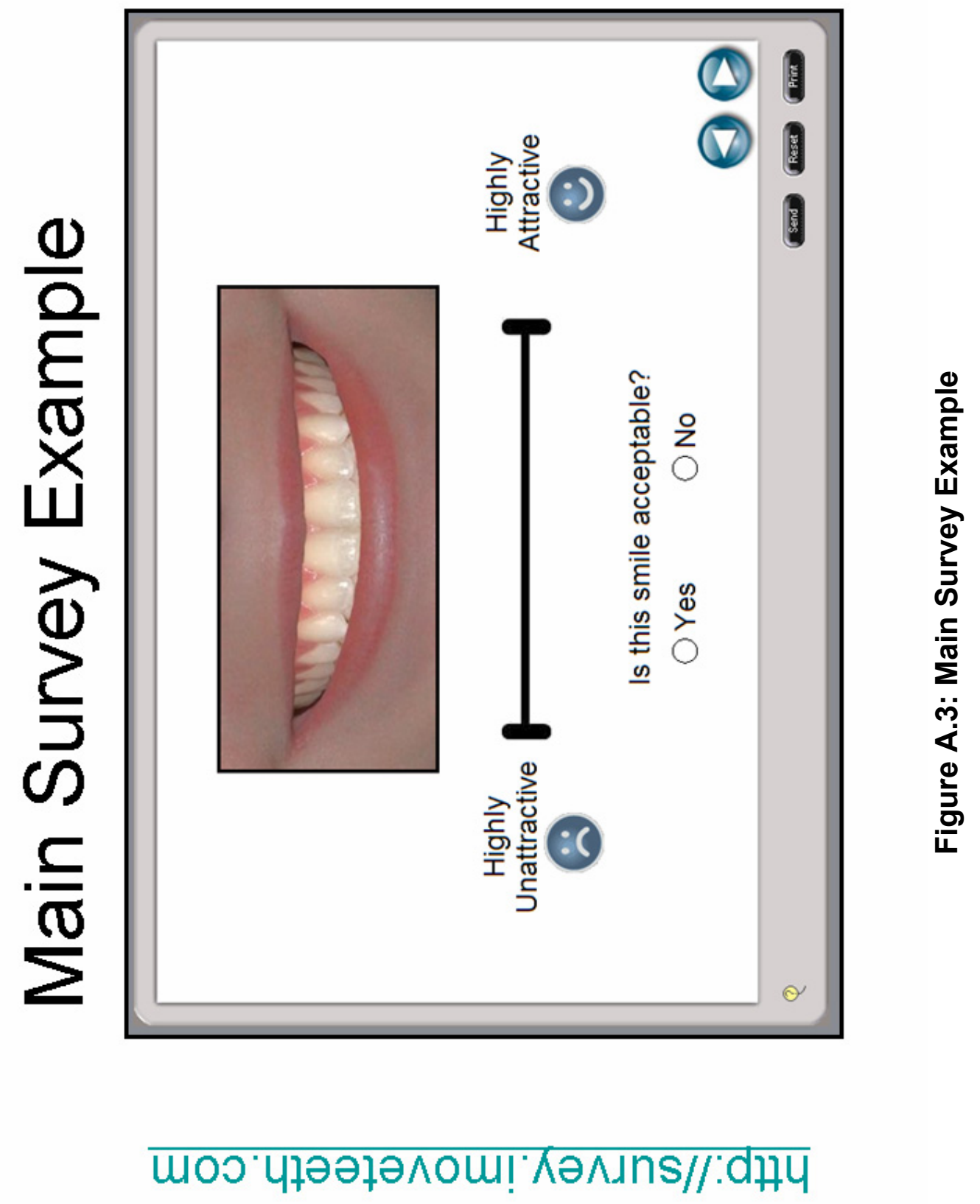

